\title{
COMARCAS Y ARTICULACIÓN DEL TERRITORIO. CUATRO EJEMPLOS ANDALUCES
}

Gabriel CANO GARCÍA y otros *

Planteamos aquí una de las posibilidades del concepto comarca como ámbito donde se generan enlaces, desplazamientos, flujos... comunicaciones entre un centro (en el que se localizan una serie de bienes y servicios) y diversos núcleos, algunos de los cuales dependen de más de una cabecera, con lo que la delimitación exacta no siempre es posible ni siquiera conveniente. Se trata de aplicar una metodología de espacio funcional, pero considerando otros criterios de Geografía Regional (natural, histórico, homogéneo...) y diferentes variables (relieve, infraestructuras, población...).

\section{APUNTES CONCEPTUALES}

\subsection{Algunas precisiones}

Existe una larga tradición geográfica sobre los denominados tipos de región, que quizás sea más adecuado llamar de espacios o territorios, porque no siempre se trata de regiones. Es preferible abordar diferentes categorías, por un lado (podríamos convenir en que sea un planteamiento "horizontal"), y distintas escalas, por otro (análisis "vertical"). Esto es más preciso y posibilita mayores cruces de variables, porque, de una parte, estarían los espacios naturales, históricos, homogéneos, funcionales, etc. y, de otra, continentes, grupos de países, estados, regiones, comarcas, municipios... Tal planteamiento permite considerar un país más o menos histórico, una región natural, una comarca homogénea...

* Este artículo resume el curso de Tercer Ciclo "Comarcalizaciones y divisiones territoriales en Andalucía” en los últimos años. Los alumnos de los mismos, cuyos nombres aparecen en el lugar correspondiente, realizaron el trabajo de campo, así como los cuatro primeros gráficos, acabados por $\mathrm{J}$. MORENO E I. ESPAÑA. 
Hecha esta distinción, conviene introducir la diferencia entre «territorio»o ámbito institucionalizado, delimitado, reconocido..., que es la escala o análisis vertical aludido antes (estados, lander, condados, provincias, etc.) y la de zonas, susceptibles de estudios «regionales», como una área montañosa, un corredor o eje, una vega..., que podríamos titular, aunque sea provisionalmente, como espacio. Ese binomio territorio/espacio no es algo aceptado totalmente, y hasta se utiliza de manera contraria a la de aquí; pero, independientemente del nombre, esa diferencia existe y genera numerosas repercusiones, porque, en última instancia, los espacios con instituciones requieren en general más atención de los organismos públicos. Y, si en otros tiempos, la territorialización, en realidad formación de estados e imperios, conllevaba fundamentalmente objetivos fiscales, militares..., hoy la delimitación debe plantearse de otra forma: conservación de la Naturaleza, ordenación del territorio, creación de equipamientos e infraestructuras, aprovechamiento de recursos mediante localizaciones óptimas en núcleos accesibles, desarrollo cultural... Y, visto así, territorializar es contribuir al bienestar de la población.

Sin embargo, como en tantos otros aspectos, la distinción espacio/territorio, u otras denominaciones que se utilicen, no siempre es clara; por ejemplo, un parque natural delimitado, planificado, institucionalizado... ¿sería espacio o territorio? Y, en el fondo, no es más que las diferencias entre las zonas apenas antropizadas, cada vez menos frecuente, y las más hechas, o deshechas, por la acción humana con todos los grados imaginables.

Una precisión más es que, con esas consideraciones, el calificativo de regional para una parte de la Geografía quizás sea inapropiado, porque no se circunscribe sólo al estudio de regiones, aunque sean éstas la escala más interesante. En efecto, en el análisis vertical la región queda en lugar intermedio, entre el mundo y un municipio, por ejemplo, confluyendo ahí casi siempre docencia e investigación (no suele haber asignaturas de niveles más pequeños) y, por eso, la necesaria comunicación e influencia entre ambas actividades es más fácil. Las regiones, al menos las de nuestras latitudes, suelen ser ámbitos más relacionados en origen con lo natural y suelen ser productos de elaboración secular y entes culturales. Son el marco adecuado para el desarrollo, sobre todo aquel que apela a lo endógeno, local, etc., para una correcta ordenación de estructuras y equipamientos, para la conservación de la Naturaleza... y, en fin, en la Unión Europea son las piezas fundamentales para acciones de equilibrio territorial.

Tendríamos así la distinción vertical o territorios (escalas de circunscripciones institucionalizadas, en las que la región o su equivalente -Comunidad Autónoma, lander alemanes, etc.- tienen un mayor peso) y la horizontal (tipos de ámbitos: naturales, funcionales, etc.) que también pueden ser espacios, dentro de territorios o abarcando uno o varios de ellos, total o parcialmente. De este modo, podríamos arrojar alguna luz hacia el controvertido concepto de región, que admitiría la acep- 
ción de territorio, donde la discusión quedaría cerrada (aunque desde un punto de vista político es inevitable apelar a otros títulos, como nacionalidad, país...) y la de espacio, donde se seguirían aplicando distintos criterios de acuerdo con las finalidades.

Ejemplos, Andalucía es, en recorrido escalar, un territorio dentro de un Estado en la Unión Europea, por arriba. Con provincias, áreas metropolitanas, Mancomunidades y municipios, por abajo. Pero en su interior hay también espacios, reales aunque no componen un ente o institución, como Sierra Morena, la Campiña de Córdoba, la Vega de Guadix o el área de influencia de Sevilla, según criterios naturales, homogéneos, históricos, funcionales... Y, como siempre, encontraremos ámbitos, en medio, de difícil catalogación, o, dicho de otra manera, de "espacios" que están pasando a ser "territorios", como la Costa del Sol o el Campo de Gibraltar, lo que sugiere una clara sucesión cronológica de procesos.

En el presente trabajo nos moveremos en la escala comarcal, según definiremos después, con especial hincapié en los elementos territorializadores aplicables a ese nivel y que fundamentalmente son el relieve, los ríos, la población, el sistema de ciudades y núcleos en general, los ejes viarios y las divisiones administrativas. Es decir, hay elementos que intervienen en mayor o menor medida en la explicación de la territorialización, lo que proporciona la entrada al epígrafe siguiente.

\subsection{Factores de territorialización}

La Geografía utiliza una buena cantidad de variables, que en su vertiente regional interrelaciona globalmente el espacio, pero apenas se reflexiona acerca de cuáles de esos elementos son factores de identificación, sustentados en la variedad terrestre, que diferencian espacios y territorios a distintas escalas.

Uno de los más evidentes es el relieve o, mejor, las formas del terreno, constituyendo las montañas elementos de separación, nada extraño, si se considera que aún hoy pueden ser obstáculos difícil de salvar, por lo que suele haber una relación directa entre antigüedad de límites y accidentes naturales. Los Pirineos o Sierra Morena son ejemplos de fronteras, pero también las montañas, sobre todo mediterráneas, aglutinan o comarcalizan, tal es el caso de la Serranía de Ronda o las Alpujarras, de forma que existe relación entre dimensiones del relieve y escala territorial y/o espacial.

Las llanuras y los valles pueden ofrecer buenas características agrarias y propiciar condiciones para el origen y evolución de poblamiento sin problemas de comunicación. A veces determinadas formas (deltas, conos de deyección, terrazas...) abren posibilidades en medios montañosos áridos y hostiles, como ocurre en una parte de la costa mediterránea andaluza. Glacis bien mecanizados, karst con 
surgencias para el regadío, cuencas sedimentarias sobre macizos ácidos... Porque una repercusión indirecta de las estructuras geomórficas, combinadas con el clima, es la capa edáfica que condiciona aprovechamientos agrarios, actividad antigua con gran repercusión en las delimitaciones; al menos en el contenido, ya que el continente depende más bien de alineaciones montañosas y cauces de importancia.

Efectivamente los ríos suelen considerarse como fronteras, y a veces lo son cuando hay dificultades de vadear, como ocurre en los cursos bajos de estuarios (Guadiana, que separa Andalucía y el Algarve) o están muy encajados. Sin embargo a menudo se olvida que las cuencas hidrográficas actúan también como elementos vertebradores (sobre todo a nivel regional) y el cauce principal deviene en eje. Tal es el caso del Guadalquivir respecto a Andalucía, que ya hace dos mil años fue percibido por Roma como la espina dorsal de la Bética. Los puentes, pasos obligados, la navegación y los regadíos han generado gran cantidad de ciudades.

Estas, y el poblamiento en general, son importantes factores de territorialización (especialmente comarcal) y el sistema de ciudades y las áreas de influencia constituyen, sin duda, elementos claves en la parte aplicada de este trabajo. Las características de la población (movimientos, naturales, migratorios, estructuras, etc.) son más contenido que continente, pero no es necesario demostrar la estrecha relación entre ambos. La manera de enlazar los núcleos, las distancia en tiempo entre ellos y, sobre todo, la localización de comercio y servicios de todo tipo (sanitarios, educativos, culturales, de ocio, etc.) repercuten notablemente, no sólo en la territorialización, sino que constituyen cada vez más los objetivos principales de ésta, principalmente de la comarcalización.

Más elementos físicos, como las costas por las relaciones comerciales y turísticas, la situación de los espacios en las grandes rutas, la aportación del clima a diversas actividades y a la calidad de vida... son variables de contenido espacial. Su pormenorización sería muy larga y se trata aquí más bien de planteamientos y teorías generales acerca de factores de territorialización, uno de los cuales, e importante, es la división administrativa.

A la escala, digamos comarcal, las circunscripciones provinciales tienen una importancia extraordinaria porque desde 1833 estos límites (con un balance territorial más negativo que positivo, como hemos escrito en otro sitio, CANO, 198790, Tomo VII) han creado intereses y costumbres que condicionan la territorialización. También las divisiones municipales, de las que es interesante conocer la extensión, sobre todo en medios agrarios, el origen respecto a otros municipios más antiguos, la homogeneidad o variedad de espacios que encierra, etc. En los cuatro casos que estudiamos después habrá ocasión de aplicar estos factores, que, corno hemos apuntado, inciden de manera diversa en la especialización/territorialización y actúan a diferentes escalas, ajustándose más a la comarcal 
las montañas medias, valles, pequeñas cuencas hidrográficas, y, sobre todo, ciudades en torno a los 20.000 habitantes.

\subsection{Tipos de espacios}

Existe una larga lista de publicaciones sobre las clases de región (mejor espacios y/o territorios, como dijimos), a los que conviene añadir algunas cuestiones y remarcar la utilidad de esa tipología en relación a la comarca. La llamada región natural cuenta con larga tradición e incluye uno o varios elementos (relieve, clima, vegetación, suelos aguas), que pueden ser contenidos y continentes. La ausencia o escasa presencia humana determinan su catalogación, pero salvo casos extremos (áreas polares, desérticas, de vegetación impenetrable) es difícil precisar cuando denominar así (hay una cierta relación inversa entre antropización y tamaño de los espacios naturales, por lo que en nuestras latitudes no suelen ocupar más de lo que se considera una comarca) y, sobre todo, cómo establecer una gradación.

Doñana es un caso evidente, pero también tiene una buena reserva ecológica parte de Sierra Morena, declarada en su mayoría como Parque Natural. Y es que, además de las características físicas de un espacio, cuenta, y mucho, la percepción del mismo, la concienciación ecológica del entorno, el tipo de administración pública (ideología y proximidad), distancia a grandes áreas urbanas congestionadas, posibilidad de turismo y ocio... Es decir, que la definición y delimitación de "lo natural" depende, dadas unas ciertas bases, de factores cada vez más numerosos. Las recientes experiencias del denominado "desarrollismo salvaje" y la puesta en circulación de teorías como desarrollo local, endógeno, sostenible... han revalorizado estos tipos de espacios, que se pretenden conservar, aumentar, recrear, utilizar con fines didácticos, recreativos y de crecimiento económico.

Son muchas las posibilidades de investigación para un geógrafo: caracterización, valorar el peso de cada variable, resaltar la más importante, interrelacionarlas, delimitar la zona, analizar la población, el entorno y sus repercusiones (no es igual un espacio natural bajo, receptor, como Doñana, que un área montañosa), posibilidades de desarrollo, etc. Es decir, se trata del análisis global del espacio, propio de la Geografía Regional, pero desde la óptica de los elementos naturales, porque esa globalidad puede conseguirse también así, además de atribuir una cierta igualdad al conjunto de variables. El conocimiento de las figuras de protección aplicadas o susceptibles de contemplar en determinados espacios es una de las metas y en las aplicaciones de cuatro casos andaluces insistiremos en la importancia de este criterio, demostrándose, al menos en uno de ellos, la estrecha relación Parque Natural/Comarca.

Las regiones históricas constituyen un modelo muy utilizado, prácticamente el único durante bastante tiempo, en los estudios regionales, porque con mucha fre- 
cuencia estos ámbitos se han convertido en entes político administrativos con límite, capital, instituciones, etc. (lo que llamábamos territorios) y casi siempre a escala regional. Esa circunstancias ofrecía un ámbito del que se estudiaba sus características y ha sido objeto (más a nivel comarcal que regional) de tesis doctorales, que contaban con algo admitido y delimitado, con estadísticas y estudios.

Lo histórico en la escala regional se utiliza con frecuencia para comparar con los ámbitos funcionales y económicos, a veces para deducir su inexistencia y/o inoperancia. En el lado opuesto este criterio se pretende como una especie de certificado que permite conseguir mayores cotas de poder político y económico, si bien no siempre se utiliza adecuadamente. Así es frecuente denominar comunidades históricas al País Vasco, Cataluña y Galicia porque aprobaron unos estatutos de Autonomía hace sesenta años (lo cual no es demasiado histórico), cuando otras vieron truncados el proyecto por la guerra de 1936. Es el caso de Andalucía, cuyo espacio fue percibido en lo esencial como diferente y se delimitó con el nombre de Bética hace dos mil años.

Escribíamos en otra ocasión (CANO, 1987-90, Tomo VIII) que el análisis evolutivo de un territorio es una especie de laboratorio donde se acumulan experiencias y se deducen acciones-reacciones espaciales, de organización... Añadimos ahora que el aval de instituciones propias y de autogobiernos en algún período histórico sí que es un elemento a tener en cuenta, porque indica lo que podemos llamar la viabilidad territorial (situación, extensión, recursos, etc.) para más o menos cotas de autonomía.

Esto vale a escala regional, porque hacia arriba (Estados) no se necesitan esas garantías en territorios que ya funcionan con la independencia que la época actual permite. Y hacia abajo (comarcas, municipios...) el criterio histórico se integra como un elemento, más o menos conocido y apreciado por la población, o, bien, puede esgrimirse para reforzar situaciones respecto a áreas colindantes. No bay que desdeñar la utilización de lo histórico a cualquier escala como elemento de desarrollo; esto es, resaltando momentos pretéritos que sirvan de estímulo, que no de arma arrojadiza. La función de algunos núcleos a lo largo del tiempo servirá para comprender mejor los territorios que se analizan en este artículo.

La homogeneidad es un criterio, más aludido que conceptualizado, que, sea de percepción directa (terreno, foto aérea, teledetección, cartografía...) o elaborada, presenta espacios con unas mismas características, pero cada variable puede homogeneizar zonas diferentes, con lo que, cuantas más coincidan en un terreno más acumulación de homogeneidad existe. Así se acercaría al concepto de región geográfica (espacio o territorio a distintas escalas, más bien), que nos parece, sin embargo, de mayor amplitud, como ya hemos escrito en otra ocasión (CANO, 198790), donde se planteaba también la metodología de delimitación. Este criterio no es el más importante para los objetivos del presente trabajo, pero lo usaremos como apoyo, sobre todo porque su utilidad estriba en que a nivel comarcal la homogeneidad en determinados elementos supone unificar soluciones. 
Existen otros criterios (sistémicos, de percepción, etc.) poco aplicados aun y es sin duda el funcional el que resulta más interesante a nuestros fines. El fundamento es sencillo, se cuentan bastantes estudios acerca de su definición y características, pero, a la hora de la aplicación y, sobre todo, de los elementos que se utilicen, hay bastante que aportar.

Se trata de la red de relaciones entre uno, o más centros, con amplia oferta de bienes y servicios y otros núcleos que carecen de ellos. La razón de la desigual distribución de los mismos radica en que cada uno exige un umbral de población y renta para su existencia. Así, una panadería puede encontrarse en cualquier aldea, pero una tienda de dietética no; la venta de tejidos y confecciones de uso diario no requiere la cantidad de habitantes de una boutique de moda; para un centro de EGB no es necesaria una ciudad grande como para una Universidad; etc.

La coincidencia en la localización de comercio y servicios suele ser lo normal por el efecto en cadena; si se quiere, como decía MYRDAL, por causación acumulativa, con lo que resultan núcleos de frecuentación dependiente del tipo de artículos ofrecidos. De esta forma hay centros con grandes áreas de influencia: Nueva York dibuja un campo bursátil mundial, en Bruselas surgen determinadas políticas para la Unión Europea, en el Parlamento de Madrid se legisla para todo el Estado en algunas materias, Andalucía es área de influencia de Sevilla en relación a competencias autonómicas, en Pozoblanco se localiza el hospital comarcal de los Pedroches, etc.

Es preciso, pues, saber qué elementos de oferta conviene analizar y a qué territorio nos referimos y, en este caso, buscamos ámbitos comarcales, por lo que, como veremos, nos interesan ofertas relacionadas con esta escala. Por otro lado, existe información sobre aspectos estáticos de cada lugar (número de habitantes, comercios, localización de centros de enseñanza y salud...), pero no hay datos de movilidad de población y de hasta donde llega la atracción de las ofertas, lo que obliga a entrevistas y encuestas para dilucidar los flujos.

\subsection{Comarcas y territorios}

Sin embargo, el concepto de comarca que se utiliza aquí no es el de un mero ámbito funcional, sino el de un espacio definido por hechos naturales, generalmente el relieve, donde algunas variables geográficas pueden presentarse homogéneamente. La población residente en un conjunto de pueblos, obtiene ciertos bienes y servicios en un núcleo, distante no más de una hora por carretera, que frecuentemente tiene un carácter histórico. Es decir, una forma de tener en cuenta los diferentes tipos de espacios haciendo hincapié en el criterio funcional.

El concepto de comarca como territorio, institucionalizado, delimitado, etc. puede ser una meta, pero antes, quizás sea preciso consolidar unos centros, previo 
estudios de situaciones sin excesiva preocupación por cerrar ámbitos. Las demarcaciones provinciales son demasiado extensas para determinadas acciones y, Ia historia desde 1833 lo demuestra, han servido para el crecimiento de las capitales a costa, generalmente, de los centros intermedios, que en Andalucía precisamente son tan importantes y constituyen una de sus identidades geográficas.

Es así que entre la provincia y el municipio hace falta un ámbito que organice mejor el territorio y potencie las ciudades medias. Necesidades municipales (basuras, cementerios, bomberos, incineradoras...), conveniencias de gestión, organizaciones de regantes, motivos económicos, etc. están llevando a uniones espontáneas en forma de mancomunidades y consorcios. Y por otra parte, las distintas consejerías de la Junta de Andalucía suelen utilizar diferentes mapas «comarcales» para su gestión, estudio, inversiones, etc.

Existen razones suficientes para que se cumpla la posibilidad contenida en el Estatuto de Autonomía sobre la comarcalización, incluso se podría modificar dos fuertes condicionantes: la rigidez del marco provincial en algunos casos y la absoluta conformidad de todos los municipios. Quizás, con un período de consolidación de centros y de seguimiento en los núcleos fronterizos, podría intentarse un mapa comarcal cerrado.

\section{LA SIERRA NORTE DE SEVILLA ${ }^{1}$}

\subsection{Delimitaciones}

Al igual que en otros casos, no hay acuerdo acerca de los límites comarcales de esta zona, pero, si nos referimos a la Sierra Norte de Sevilla, es fácil enmarcarla en la parte septentrional de la provincia, entre Huelva, Córdoba y Badajoz. La indefinición quedaría al sur, donde los términos municipales no siempre se atienen a la diferenciación geológico-topográfica sierra/valle, sino que suelen abarcar a ambos como espacios complementarios.

Existe una infinidad de divisiones y comarcalizaciones, sobre todo en los años sesenta, que no suelen coincidir (distintos Ministerios, estudios, entidades financieras... CANO, Geografía de Andalucía, 1987-90, tomo VII) y la propuesta de la Junta de Andalucía, 1983, comprende las comarcas de CAZALLA (con ese municipio más Alanís, Guadalcanal, y San Nicolás), CONSTANTINA (Pedroso y Navas de la Concepción) y CASTILLO DE LAS GUARDAS (con Real de la Jara, Almadén de la Plata, El Ronquillo, El Garrobo y El Madroño), además de Guillena (Castilblanco y Gerena), serrana sólo en su parte norte. El Parque Natural abarca

1. Hicieron el trabajo de campo en esta comarca: D. COBOS, A. GOMEZ, A. MAZUECOS, L. SANZ y V. ZAMORA. También P. Hernández, A. Malagón y S. Senra. Curso 1991-92. 
total o parcialmente los municipios de las dos primeras más los dos iniciales de la tercera.

Por su parte, la Mancomunidad de municipios, creada en marzo de 1992, abarca esos nueve más Puebla de los Infantes y pretende potenciar el desarrollo de la zona, mediante equipamientos e infraestructuras orientadas fundamentalmente a un turismo rural compatible con la conservación. Acciones concretas se ligan a la dotación de maquinarias agrícolas, recuperación de vías pecuarias, construcción de casas forestales, promoción de voluntariado ambiental... y un proyecto Fourstar, en colaboración con el Fondo Social europeo, de cualificación profesional de jóvenes. En cuanto a capitalidad, es significativo que se constituyese una primera sede en situación excéntrica (El Real de la Jara) y una segunda instalación en Cazalla.

Sobre publicaciones específicas de la zona, MARTIN, 75, se refiere a la Sierra (15 municipios completos y 12 parciales con un total de $4.000 \mathrm{Km}^{2}$ ), mientras que REQUENA, 93, matiza bastante: cuenta un máximo de 18 términos y un total de $3.750 \mathrm{Km}^{2}$, a efectos físicos, pero se refiere a la población de 15 y se ciñe para determinadas cuestiones a los nueve del Parque Natural.

Recordemos que Sierra Morena queda fraccionada en interfluvios por cauces de dirección armoricana NW-SE, uno de los cuales, el Viar, divide la zona sevillana en dos, recorridos por sendas carreteras N-S, que orientan los flujos y las relaciones. La parte occidental, de pueblos que no llegan a 2.000 habitantes, enlaza rápidamente con Sevilla, mientras al Este puede hablarse de una comarca centrada por Constantina y/o Cazalla, en torno a ocho y cinco mil, respectivamente.

En principio, pues, hay que distinguir aquí cuatro tipos de espacios, teniendo en cuenta varios factores de territorialización (montañas, ríos, límites forestales, vías de comunicación, poblaciones, términos municipales, provincias, agrupaciones locales...). A) La Sierra Norte, concepto natural con circunscripciones provinciales, excepto al sur (valle del Guadalquivir). B) El Parque Natural, que comprende gran parte de la Sierra y se delimita, total o parcialmente, por nueve municipios. C) Mancomunidad, bastante coincidente con el Parque, salvo La Puebla, difícilmente asignable a la Sierra. Y D) La posible comarcalización funcional, que nos parece se ciñe a la parte oriental del Viar con dos áreas o, más bien, una bicéfala.

\subsection{Un espacio forestal}

La Sierra Norte forma parte del macizo hespérico, de antiguos materiales correspondientes a la era primaria, distinguiéndose dos zonas separadas por el Viar, como dijimos. Al este predominan pizarras y cuarcitas y, al oeste, aparecen extensas manchas de rocas intrusivas (granito, diorita...). Es la incisión de esa arteria fluvial la que origina las pendientes más fuertes, si bien la mayor parte de la Sierra tiene desniveles moderados, con formas redondeadas, superficies de erosión y 
relieves apalachienses (REQUENA, 93) y, en conjunto, la altitud sobre el nivel del mar apenas llega a los 1.000 metros en la Sierra del Viento, junto a Guadalcanal.

Suficiente para recibir más precipitaciones que el Valle (superiores a $700 \mathrm{~mm}$. anuales con alguuos escarpes que sobrepasan los 1.000) y contar con unos cuatro grados menos de temperatura media anual (entre 14 y $18^{\circ} \mathrm{C}$ ), aunque la del verano es alta (24-28). El valor de la Sierra Norte como reservorio hídrico es de capital importancia y dá lugar a varios embalses (Retortillo, Huéznar, Cala...); no obstante, la pobreza de los suelos y lo escarpado del terreno explican las escasas zonas cultivadas de secano (alrededor del $18 \%$, la más importante se sitúa en Guadalcanal-Alanís) y el desarrollo de una vegetación arbórea tipo frondosa, que ha sido estudiada detalladamente por REQUENA, 1993. Casi el $60 \%$ del espacio es forestal, predominantemente natural, aunque antropizado, del tipo quercus (252.000 Ha. de encina, alcomoque, piruétano... de bosque adehesado), unas 30.000 ha. de eucaliptos y la mitad de pinos repoblados.

Las diferentes políticas forestales realizadas desde principios de siglo, en un régimen de propiedad particular de hasta un $90 \%$, desembocan recientemente en el binomio conservación/desarrollo promovido por la Comunidad Europea, seguido por el Plan Forestal Andaluz de 1989 y la declaración de Parque Natural por el Parlamento Autonómico. En las nuevas estrategias de desarrollo aparecen la funcionalidad económica (ganadería en dehesas, caza y pesca fluvial), usos sociorecreativos y conservación de la Naturaleza con la promulgación del parque, que cuenta con $164.840 \mathrm{Ha}$. y nueve términos municipales (total o parcialmente) con un total de 32.000 habitantes. La puesta en marcha del proyecto LEADER permite subvenciones de estructuras y equipamientos con apoyos al desarrollo local, turismo, empresas... (REQUENA, 93).

\subsection{Escasez de población}

Este espacio ha estado tradicionalmente poco poblado con una economía minera (hierro, mármol...) y silvo pastoril, que recientemente se ha visto afectada por emigraciones y evolución negativa demográfica, de tal forma que algunos municipios no alcanzan los $10 \mathrm{~h} . / \mathrm{Km}^{2}$ y apenas se superan los 25 en el mejor de los casos. Los quince municipios que incluye REQUENA en la Sierra Norte pasaron de 71.942 en 1950 a 37.284 en 1991 (los nueve del Parque, 26.525 en 1995), constituyendo una de las comarcas andaluzas de mayor envejecimiento y pérdida demográfica. Y la evolución en los dos núcleos mayores ha sido incluso peor: Cazalla descendió de 11.347 a 5.018 en ese período (es decir perdió casi el $60 \%$ ) y Constantina bajó de 14.619 a 7.519 . No hay, pues, un centro claramente destacado que mantenga una oferta suficiente de servicios, cuando, además, Sevilla se encuentra cada vez a menos tiempo por carretera. 


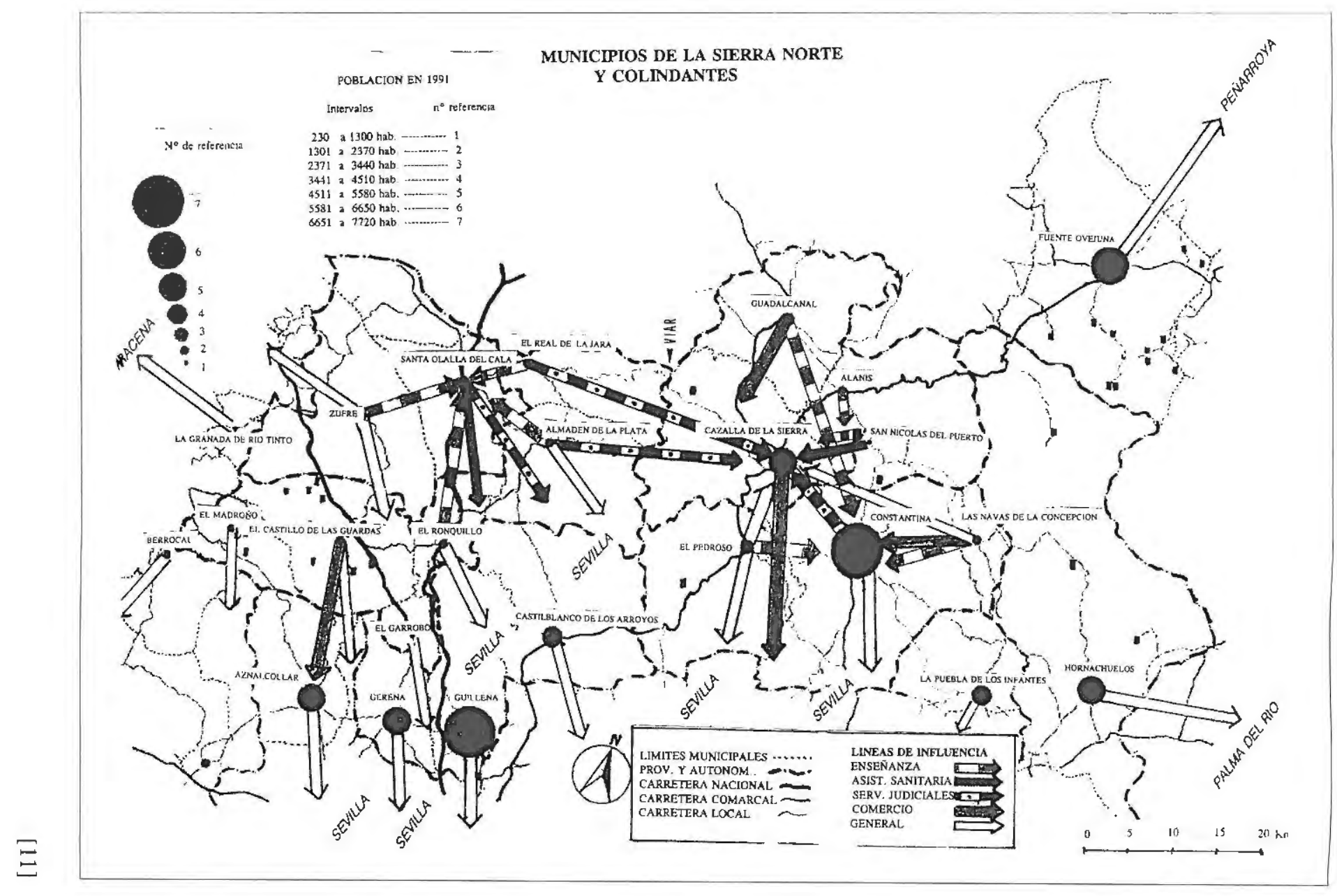




\subsection{Ejes naturales y viarios}

Sierra Morena queda dividida, como dijimos, en espacios de dirección NO-SE, que por esta zona son de oriente a occidente: valle del Bembézar, en Córdoba, Sierra Alta, río Retortillo (límite provincial), Sierra del Agua, Rivera del Huéznar, Sierras de la Grana y Pedroso, valle del Víar, Sierra Padrona, Rivera del Cala (límite Sevilla-Huelva) y Rivera de Huelva. Condicionados por estas estructuras, hay dos ejes viarios fundamentales norte-sur en relación al Viar, que determinan la existencia de, por lo menos, dos áreas desde el punto de vista funcional.

Una, la carretera de la Sierra, de Sevilla a Constantina y Cazalla por El Pedroso, y, la otra, hacia Mérida con enlaces a pequeñas poblaciones (ninguna de las citadas llega a 2.000 habitantes en el último Censo) conectadas rápidamente con Sevilla, por lo que se trata de un espacio difícilmente asimilable a la "Comarca" de la Sierra Norte. Si acaso, Almadén de la Plata y El Real de la Jara, por formar parte del Parque Natural, junto con las siete entidades del eje citado en primer lugar, donde se sitúan dos poblaciones de cierta importancia, que se disputan la capitalidad de la zona.

\subsection{Divisiones administrativas y de otro tipo}

Se sabe que en la época califal la Sierra Norte formaba una demarcación, o kora, denominada Firrish, y a finales del XVI constituía una circunscripción fiscal con centro en Cazalla, que es capital de partido judicial desde 1834. El estudio sobre espacios históricos andaluces (POSADAS y GARCIA, 1990) marca claramente los siete municipios de las dos comarcas propuestas por la Junta de Andalucía en 1983, por lo que el criterio histórico pesa, junto al natural.

En las 12 comarcalizaciones de los años sesenta Cazalla se repite bastante más y capitaliza un área judicial con los municipios incluidos en el Parque Natural, que, con Puebla de los Infantes (ya prácticamente en el Valle y muy cerca de Palma del Río) son los beneficiarios del Programa LEADER.

Las diferentes áreas homogéneas (véase tomo VII citado) marcan la Sierra para algunas variables (sobre todo demográficas. La dinámica poblacional -JORDA, 90 señala el Parque), si bien en muchos casos comparte características de Sierra Morena en general y, en otros, el límite del Viar divide claramente dos áreas (algunas comerciales, distrito telefónico...).

La funcionalidad dibujada en ese mismo volumen, insiste en los dos ámbitos y atribuye a Cazalla o Constantina diferentes centralidades. Así mismo, las áreas gravitacionales (Grupo de Investigación ESTUDIOS GEOGRAFICOS ANDALUCES, 1994) asigna el Este del Viar al centro Lora del Río y el Oeste a Sevilla. Algo parecido al resultado de las variables estudiadas (electrodomésticos, vesti- 
dos, abogados, llamadas telefónicas) en el Sistema de Ciudades (1986), que conducen a la propuesta de un área con centro intermedio en Lora del Río con tres comarcas, dos de ellas con capital, como dijimos, en Cazalla y Constantina.

\subsection{Oferta de servicios y flujos}

La escasa importancia del poblamiento no hace suponer en principio una oferta amplia de servicios y, para su conocimiento, hemos añadido a lo publicado en el referido tomo octavo de la Geografía de Andalucía las entrevistas realizadas por los alumnos de Tercer Ciclo (cuyos nombresya se han citado) entre comerciantes, componentes de la corporación municipal, profesores, etc.

Ciñéndonos a la parte oriental, concretamente a lo que es el Partido Judicial de Cazalla, donde hay notaría y abogados, existen Centros de Salud y Farmacias en todos los municipios y, en los mayores, sobre todo en las dos capitales, médicos especialistas, pero no hay un hospital comarcal. En educación, aparte la EGB con presencia generalizada y algunos colegios privados, se cuentan con centros de Media y Formación Profesional en los dos núcleos importantes, Cazalla y Constantina, hacia donde se dirigen indistintamente los usuarios de Guadalcanal, Alanís, Las Navas, San Nicolás y El Pedroso, mientras los del Real y Almadén giran más hacia Santa Olalla, provincia de Huelva, con quien están mejor comunicados.

Entidades financieras, sobre todo Cajas de Ahorros, hay en todos los pueblos, contabilizándose en cada uno de los dos núcleos centrales unas seis o siete. También agentes comerciales, de seguros e inmobiliarias, así como comercio de frecuencia diaria y semanal, pero para artículos especializados se viaja a Sevilla, mientras que los de escasa especificidad (electrodomésticos, muebles...) no se encuentran mucho más allá de las dos cabeceras. Igual ocurre con materiales de construcción y maquinarias agrícolas, en lo que destaca también Guadalcanal, que centra la zona agraria más importante de la Sierra.

En cuanto a flujos, la parte occidental aprovecha la carretera Sevilla-Mérida para desplazarse hacia la capital o, según qué artículos, para Guillena, Gerena, Camas... y la zona norte, como Almadén y Real de la Jara, hacia Santa Olalla. No existen relaciones transversales a ambos lados del Viar, más que la obligada de tipo judicial para Almadén y El Real hacia Cazalla. Esos dos municipios difícilmente pueden considerarse integrados en el ámbito oriental, donde se incluyen Guadalcanal, Alanís, El Pedroso, Las Navas y San Nicolás, además de Constantina y Cazalla, que centran esta Comarca.

Si bien parece que la historia reciente de cabecera judicial pesa y la percepción desde los distintos pueblos (incluidos algunos entrevistados de Constantina) es que Cazalla es la capital. También existe una opinión generalizada (así mismo en la parte occidental, donde la capitalidad no siempre se asigna) de que la Comarca es la "Sierra Norte". 


\subsection{Resumen}

Se confirma lo que planteábamos al principio: la Sierra Norte es una realidad natural percibida en la zona y, por supuesto, desde Sevilla, que cuenta cada vez más con ese espacio natural y de ocio. Las estructuras de Sierra Morena dificultan las relaciones transversales y el Viar marca dos ámbitos diferentes, recorridos por sendas carreteras y remarcados por la historia. El occidental está incluido claramente en el área de Sevilla bastante más que el oriental, que mantiene cierta autonomía y reparte la capitalidad entre Constantina y Cazalla, aunque parece que cada vez más decantándose por ésta, que es de mayor historicidad (MIRANDA y JURADO, 1990) y ostenta de hecho la cabecera de la Mancomunidad.

Esta agrupación dá lugar a unas acciones comunes de desarrollo y coincide bastante con el Parque Natural, por lo que marca sobremanera el área, cuyo futuro está muy ligado a la oferta de ocio y turismo en relación fundamentalmente con Sevilla y su entorno. Si bien aspectos como la reserva hídrica, una cierta promoción agroindustrial (matadero comarcal) y la potenciación cinegética tampoco son desdeñables. Tales circunstancias, más el punto de vista funcional (principal aportación de este trabajo), parecen desaconsejar el fraccionamiento comarcal planteado por la Consejería de Obras Públicas en 1983, debiéndose considerar un espacio, de capitalidad dual, más o menos coincidente con el Parque y la Mancomunidad.

\section{EL CORREDOR SEVILLA-JEREZ ${ }^{2}$}

Se trata de averiguar la organización de flujos y áreas de influencia en un eje como el propuesto, que une dos importantes ciudades por medio de autopista y carretera, en torno a las que se insertan algunos núcleos relevantes como Lebrija. Lógicamente los dos polos del pasillo organizan un espacio amplio; la frontera occidental se define por un hecho natural (el borde de un antiguo lago, hoy marisma); y al este existen centros competidores, Utrera, Villamartín y Arcos, cuya influencia hacia el eje se intentará discernir.

\subsection{Una orilla poblada desde antiguo}

Buena parte del corredor bordea la otrora orilla del Lago Ligustinus, existente hace unos dos mil años, y colmatado posteriormente. Colinas y cabezos del

2. Son coautores de esta parte: R. BRENES, I. ESPAÑA, L. MERINO y A. SANTAOLALLA. Curso 1992-93. 
mioplioceno sirvieron de antiguos asentamientos en el borde lacustre y en más de una ocasión actuaron de vigías, destacando desde antiguo la Nabrissa turdetana citada por Estrabón.

En la actualidad es el núcleo mayor del eje con 24.000 habitantes, seguidos de Las Cabezas con 16.000 y, si se suman Los Palacios (31.000) y Trebujena, se alcanzan casi los 80.000 pobladores. Y no es de las zonas menos densas de Andalucía ni tampoco de las que haya perdido población, si no que su evolución ha sido positiva en las décadas de fuertes emigraciones. Sin embargo, los municipios periféricos de Espera y Bornos (unos 12.000 en total) han decrecido, sobre todo desde los años setenta.

Las buenas condiciones topográficas y la existencia de ciudades importantes explican la red viaria, que ofrece lo siguiente: ferrocarril Sevilla-Cádiz, carretera entre esos núcleos, comarcal de Las Cabezas a Sanlúcar por Lebrija y Trebujena y, finalmente, autopista de peaje. Desde Los Palacios hay desvío a Utrera; y de Las Cabezas, hacia Espera y Bornos, de donde casi a la misma distancia se puede ir a Villamartín o Arcos.

\subsection{Un espacio de agricultura regada}

El mantenimiento demográfico, cuando menos, se debe fundamentalmente a las buenas condiciones para la agricultura. Efectivamente, el relleno de la antigua laguna con limos proporciona unos suelos aptos para arroz y, posterionmente, otros cultivos, especialmente industriales, que generan puestos de trabajo y una cierta industria agroalimentaria, fundamentalmente en Lebrija. El canal del Bajo Guadalquivir y sus derivados organizan una red de riego en la llanura cuaternaria, mientras que la zona de margas y margo-calizas miopliocenas son asiento de cultivos de secano.

Hay que añadir un clima propicio de $18-20^{\circ}$ de temperatura media anual y un "invierno" de $10^{\circ}$ de media de enero. Estamos, pues, ante un espacio cultivado en alrededor del $80 \%$ de las superficies municipales, con importancia (lo que no es muy frecuente en Andalucía) de las explotaciones de 5-20 Ha., y altos índices de mecanización.

Como ocurre en otros casos, la estructura municipal abarca espacios complementarios y, así, de oeste a este se suceden entre Los Palacios y Trebujena la llanura de limos cuaternarios regados, las colinas miopliocenas, predominantemente de secano y, en los términos centrales de Lebrija y Las Cabezas, más amplios, relieves triásicos sin cultivar. 


\subsection{Variabilidad administrativa}

Históricamente esta zona ha dependido de Sevilla y en la época califal se cita el núcleo de Nebrija, pero (a diferencia, por ejemplo, de Constantina, Ecija, Carmona o Morón, que encabezaban respectivas koras o provincias) no era capital de ninguna demarcación. Tampoco en la división fiscal de finales del XVI, donde, además del citado, constan como pueblos de cierta importancia Los Palacios, Las Cabezas, Trebujena, Espera y Bornos. Estos tres ya estaban dentro del Partido de Jerez en el Censo de Floridablanca, 1785, mientras el resto pertenecían a Sevilla, diferenciación que se consolida en la provincialización de 1833.

$\mathrm{Al}$ institucionalizarse los partidos judiciales un año más tarde, se asigna la parte sevillana a Utrera, a quien corresponde hasta 1988, en que por primera vez existe

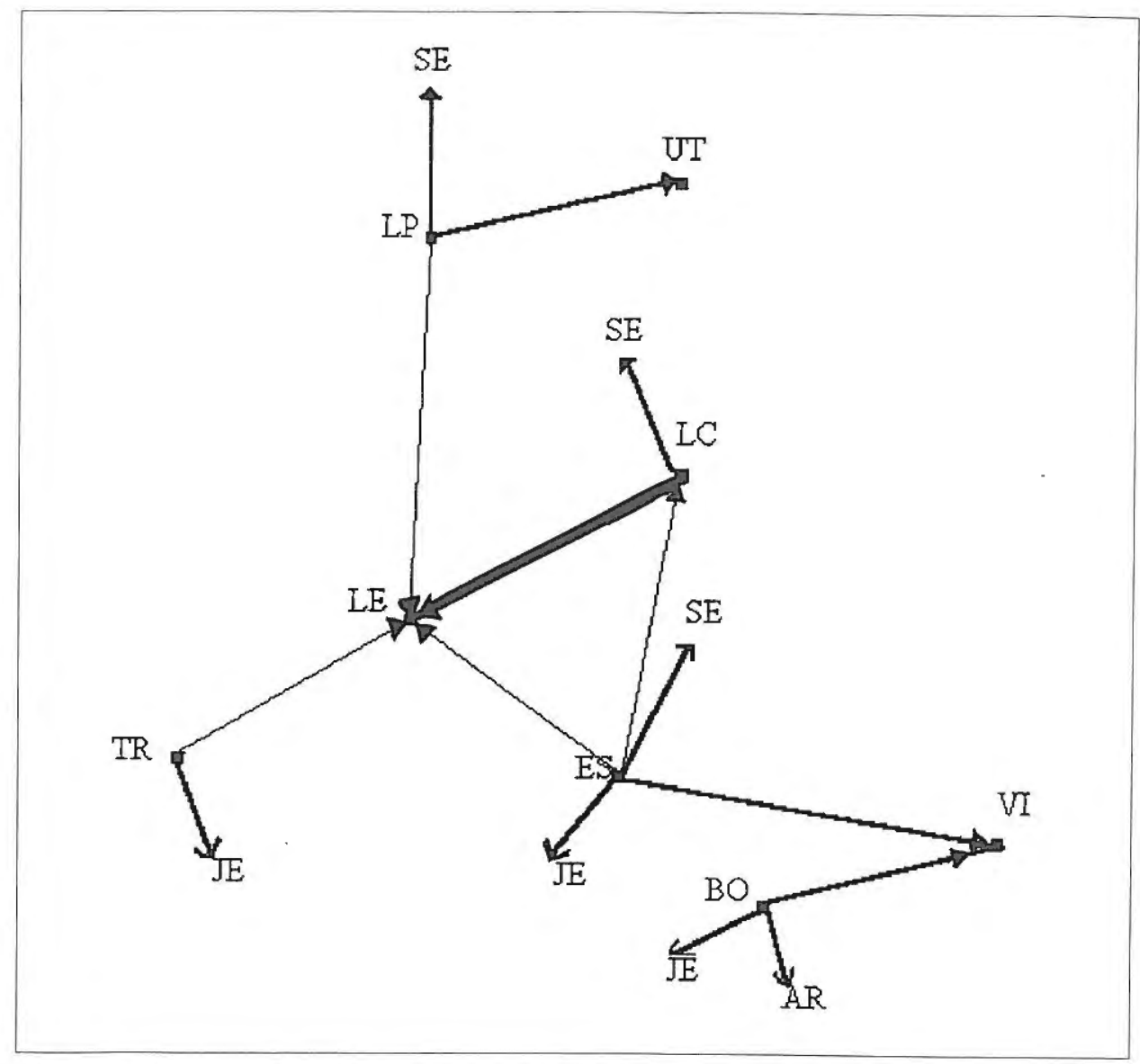

Tres grados de intensidad de relaciones en el eje Sevilla-Jerez. 
una circunscripción así formada por Lebrija y Las Cabezas. Los Palacios siguen en Utrera, Trebujena en Sanlúcar, Espera y Bornos en Arcos; y en las distintas comarcalizaciones de los años sesenta (Véase el tomo VII de la Geografía de Andalucía citada) suele aparecer esta zona incluida en Utrera o Sevilla con Ia denominación de Campiña o Marisma.

La propuesta de la Junta de Andalucía en 1983 dibuja las siguientes comarcas: UTRERA con Los Palacios y Los Molares (le faltaría El Coronil para coincidir por el partido judicial), LEBRIJA con Las Cabezas, JEREZ con Trebujena, y ARCOS con Espera y Bornos, entre otros.

\subsection{Homogeneidad y funcionalidad}

En el citado tomo octavo de la Geografía de Andalucía puede constatarse la homogeneidad de la zona, que destaca en algunas variables, generalmente de forma positiva, pero unas veces se señala el corredor (cuota de mercado, MARQUEZ DOMINGUEZ, 1990) y otras, la parte central del mismo (accesibilidad, frecuentación hospitalaria, LOPEZ LARA, 1990...).

La funcionalidad estudiada por el Sistema de Ciudades, 1986 aporta poco: Los Palacios, Las Cabezas y Lebrija están con Sevilla en la estructura de llamadas telefónicas y en el área de electrodomésticos (pero Las Cabezas depende de Utrera y en vestidos de Lebrija), dibujándose una zona de nivel intermedio con base en Utrera, y dos comarcas; una de ellas con los municipios de Lebrija y Las Cabezas, que es la propuesta de la Junta de Andalucía en 1983.

\subsection{Servicios y desplazamientos}

Las entrevistas se hicieron sobre el cuestionario adjunto en los pueblos de Los Palacios, Las Cabezas, Lebrija, Trebujena, Espera y Bornos a personas cualificadas (profesores, Ayuntamiento, notario, en su caso, etc.) y a dueños o empleados de establecimientos donde se supone iban a comprar o adquirir servicios habitantes de otras poblaciones.

En el caso de Los Palacios y Villafranca la respuesta más generalizada acerca de a qué comarca se pertenece es a la que encabezaría la propia localidad, o bien se indica la escasez de conciencia comarcal. En otros casos se señala a Utrera por inercia histórica (juzgados, delegaciones administrativas...), Lebrija, como cabecera de la Mancomunidad del Bajo Guadalquivir, o Dos Hermanas, donde la localización del Hospital Valme condiciona los desplazamientos sanitarios. En general para la adquisición de bienes y servicios no existentes en el pueblo se acude más a Sevilla, a poca distancia por autopista, y hacia donde hay buena frecuencia de 
autobuses; algo menos al sur (Lebrija, Jerez...) y con escasa asiduidad hacia Utrera, que, como centro de polarización, no va mucho más alla de las propias pedanías y cuenta para pocas cosas con procedentes de Las Cabezas.

El mismo condicionante sanitario existe para este último núcleo, que, con sólo Centro de Salud, dirige flujo hacia Dos Hermanas, al igual que a Sevilla para muchos bienes, pero se nota, desde luego, una mayor relación con Lebrija (hipermercados, electrodomésticos, muebles, hogar, gestorías, notaría, academias, funerarias...), a la que reconocen como capital comarcal.

Trebujena se inserta claramente en el área de Jerez, de la que algunos entrevistados consideran una barriada, y tan sólo para ciertas cuestiones muy específicas depende de Cádiz o genera flujos esporádicos hacia Sanlúcar y muy escasos hasta Lebrija. El caso de Bornos también aparece indudablemente ajeno al eje que consideramos, aunque además de Jerez, polo predominante, conecta con Arcos y Villamartín.

Espera es un caso típico de núcleo fronterizo, al encontrarse equidistante entre varios centros, si bien se relaciona mucho más con los de su provincia, debido a condicionantes administrativos, sanitarios, etc. Lógicamente, Sevilla y Jerez se perciben como los polos de mayor especialización; y, en segundo lugar, Arcos, Bornos (a los que se consideran vinculados comarcalmente) y Villamartín. Más alejados en las preferencias, Dos Hermanas, Los Palacios y Las Cabezas, mientras que con Lebrija apenas hay conexiones.

La "capitalidad" de la antigua Nabrissa como centro del eje no traspasa, pues, los límites de su término y el de Las Cabezas (incluida la pedanía de El Cuervo), aunque en algunas entrevistas se alude a desplazamientos desde Trebujena y Espera e, incluso, se detectan alumnos de otros municipios, tanto en el centro de BUP, como en el de Formación Profesional.

Lebrija tiene una importante oferta de bienes y servicios, sobre todo comparativamente con el entorno, aunque, no hace falta recordarlo, para cuestiones especializadas depende de Sevilla. La capitalidad de la Mancomunidad de Municipios del Bajo Guadalquivir (formada por diez localidades) proporciona a Lebrija, por su situación, una centralidad agraria, que se viene potenciando a través de programas de desarrollo local y de relaciones internacionales (iniciativa comunitaria Horizan, Euroforum...), planes comarcales, etc. de formación y promoción.

No obstante, y de momento, parece que los dos polos del eje Sevilla-Jerez sólo dejan margen de polarización a Lebrija con Las Cabezas, mientras que las conexiones con Trebujena y Espera, además de la competencia de Jerez, cuentan con el obstáculo del límite provincial. 


\section{CUESTIONARIO SOBRE DESPLAZAMIENTOS}

Pueblo o ciudad donde la población adquiere:

\section{ARTícUlos}

- Comestibles especializados.

- Confección.

- Zapatería.

- Electrodomésticos.

- Muebles y hogar.

- Deprotes.

- Material de construcción.

- Ordenadores, informática.

- Librería y otros.

- Optica.
ADMINISTRACIÓN, ENSEÑANZA, ETC.

- Notarios.

- Abogados.

- Juzgados.

- Centros BUP.

- Centro FP.

- Academias.

- Colegios privados.

- Ambulatorio.

- Hospital.

- Médico general.

- Médico especialista.

¿A QUÉ COMARCA PERTENECE EL PUEBLO?

¿CUÁL ES LA CAPITAL DE ESA COMARCA?

\section{EL ANDEVALO 3}

\subsection{Planteamiento}

Se trataba este curso de aplicar los conceptos y métodos de territorialización a un espacio amplio, poco articulado y que, en principio, parecía estar polarizado parcialmente por Valverde del Camino, un pueblo dinámico, de 12.000 habitantes y cruce viario, como indica el topónimo. Al igual que en los otros casos, se une al conocimiento de la zona las entrevistas realizadas por los alumnos de Tercer Ciclo del curso 1993-94.

El extremo occidental de Andalucía ha constituido tradicionalmente un espacio marginal en diversos aspectos (comunicaciones, agricultura...) y mucho más dependiente, si cabe, que el resto. La minería colonizadora y una industria-enclave definen bien esa situación, que ha cambiado apreciablemente en el litoral durante las últimas décadas, como en el almeriense extremo oriental.

No así el resto de la provincia, que, por otra parte y en consonancia con ese carácter periférico, tiene límites un tanto artificiales y capitalidad discutida en su

3. Han colaborado: E. BARQUERO, I. CASTRO, A. GARCIA PAZOS, C. GRANADOS, C. JANEIRO, J. MORENO Y P. PLAZA. Curso 1993-94. 
origen (CANO, 1992). En cualquier caso, es frecuente señalar tres grandes áreas transversales en esta circunscripción: la Sierra, el Andévalo y la Campiña-litoral o Tierra Llana.

\subsection{Una amplia penillanura}

Como suele ocurrir en las situaciones intermedias, el Andévalo es de difícil demarcación y así lo subraya DIAZ DEL OLMO, 1986, que lo delimita como sigue. Por la vertiente meridicional de Sierra Pelada, del Mustio a Almonaster en dirección W-E para girar hacia el sur, quedando La Granada y Campofrío como "puertas de la Sierra..." (AVILA, 1981). Por el oeste, la demarcación se desvía al norte hacia Rosal de la Frontera por influencia de la cuenca del Chanza.

El límite sur se sitúa en el contacto paleozoico-terciario con las consecuencias de aprovechamiento agrario consiguiente; en uno, predominio de pizarras y cuarcitas y, en eI otro, conglomerados, gravas, arcillas, margas... La separación ni es recta ni continua, pero, grosso modo, puede alinearse entre el sur de Villanueva de los Castillejos y el norte de Tejada.

La antigüedad de los materiales explican una morfología aplanada en varios pisos y alineaciones transversales de intrusiones graníticas y dioríticas, lo que, aparte algunos escarpes y encajamientos, es una topografía que favorece las comunicaciones. Sin embargo, la capa edáfica del antiguo macizo hespérico, como en toda Sierra Morena, produce suelos poco fértiles para la agricultura.

\subsection{Minería y pobreza agraria}

En cambio la constitución geológica ha originado abundantes yacimientos minerales, explotados desde antiguo, aunque con escaso beneficio para la zona, sino más bien con fuerte degradación del paisaje y ausencias de alternativas a la crisis de las extracciones. En realidad todo el norte del Andévalo es zona minera, si bien (además de otros núcleos, como Puebla de Guzmán y el mismo Valverde) se remarcan dos sectores fundamentales (DIAZ DEL OLMO, 1986): uno en Tharsis, Calañas y Villanueva de las Cruces; y el segundo, en Riotinto, Nerva y Zalamea.

Existen bastantes estudios sobre la historia y actualidad de esta minería, especialmente la de Riotinto (GIL VARON, 1984), y se conocen los aprovechamientos prehistóricos, las relaciones con el mundo tartésico... hasta llegar a la colonización del XIX y las masivas extracciones, generalmente a cielo abierto, de piritas, cobre, plomo, oro, plata... con los movimientos demográficos consiguientes, las transformaciones paisajísticas y, también, las construcciones viarias y las influencias en el polo industrial de Huelva. A nuestros efectos, veremos las repercusiones de estas dos zonas mineras en la articulación del territorio. 
La agricultura, por el contrario, no es aquí un factor de territorialización, dado que, por lo general, el roquedo cuarcítico y granítico produce una capa edáfica débil, con exiguos horizontes, poca potencia y, en todo caso (aun en las pizarras y otros materiales con mayor posibilidades de edafización), se trata de suelos ácidos poco aptos para el cultivo. $\mathrm{Y}$ eso que el clima no se diferencia mucho del Valle del Guadalquivir; a lo sumo, un par de grados menos de T.m.a. con la misma media de enero y prácticamente iguales precipitaciones.

En efecto, el regadío es muy escaso en el Andévalo (unas $600 \mathrm{Ha}$.) y el secano predominante es de tipo extensivo, mientras las repoblaciones de eucalipto (MARQUEZ, 1977) han ocasionado bastantes problemas y el bosque restante, como el de Sierra Morena, no genera una actividad especial de cara a la territorialización.

No es de extrañar, pues, que desde los años sesenta el Andévalo tenga tasas negativas de evolución demográfica, atenuadas últimamente, e incluso con cierta recuperación en la parte occidental, además de Valverde. Así que éste, junto con algún otro de la Cuenca minera, supone un enclave de mayor densidad en una zona poco poblada, como casi toda Sierra Morena.

\subsection{Indiferenciación administrativa}

En el Califato de Córdoba Niebla fue un núcleo importante, cuya kora abarcaba la actual provincia de Huelva, excepto la Sierra, y donde el Andévalo estaba prácticamente despoblado. A finales del XVI el territorio fiscal coincide con el andalusí y en el Censo de Floridablanca, 1785, toda esa zona pertenecía sin diferenciarse, al Reino de Sevilla. En 1834 aparece el partido judicial de Valverde, que hasta hoy abarca el conjunto del Andévalo.

Las comarcalizaciones estudiadas en el tomo VII de la Geografía de Andalucía señalan variedad de situaciones, que remarcan la menguada especificidad. Así en unas consta el Andévalo (con esa denominación o añadiendo la de Cuenca Minera); en otras, dos partes, generalmente llamadas occidental y oriental y, en varias, distintas combinaciones. La propuesta de la Junta de Andalucía en 1983 incluye cuatro comarcas: Nerva, Valverde, Puebla de Guzmán y Villanueva de los Castillejos.

Los mapas de homogeneidad, contenidos en el tomo VIII de la publicación tantas veces citada, diferencian dos zonas en el Andévalo (tamaño de las explotaciones, cuota de mercado, accesibilidad por carretera, frecuentación hospitalaria, oferta educativa básica... Véase LOPEZ PEREZ y VENTURA, además de los ya citados). Por su parte las áreas gravitacionales (EST. GEOGR. ANDALUCES) indican dos ámbitos, pero no este/oeste: uno, centrado por Valverde y, otro, por Nerva (la comarca de la Junta de Andalucía, 1983, salvo Zalamea). 


\subsection{Polarizaciones y ofertas}

Valverde del Camino es el centro más importante del Andévalo en situación de cruce viario y en posición central de la provincia, con algunas vegas y, sobre todo, una artesanía e industria modernizadas, especialmente de mnebles y calzados (los famosos botos camperos), herrería artística, confitería...

Las respuestas al cuestionario adjunto, utilizado en el trabajo de campo, fijan múltiples servicios en mayor o menor grado, excepto en Hospital, cierta administración estatal y autonómica más enseñanza universitaria. En algunos casos la oferta es muy amplia: calzado y mueble, por ser centro de fabricación, así como agentes comerciales, empresas de transportes y talleres de reparación, en relación a la situación viaria.

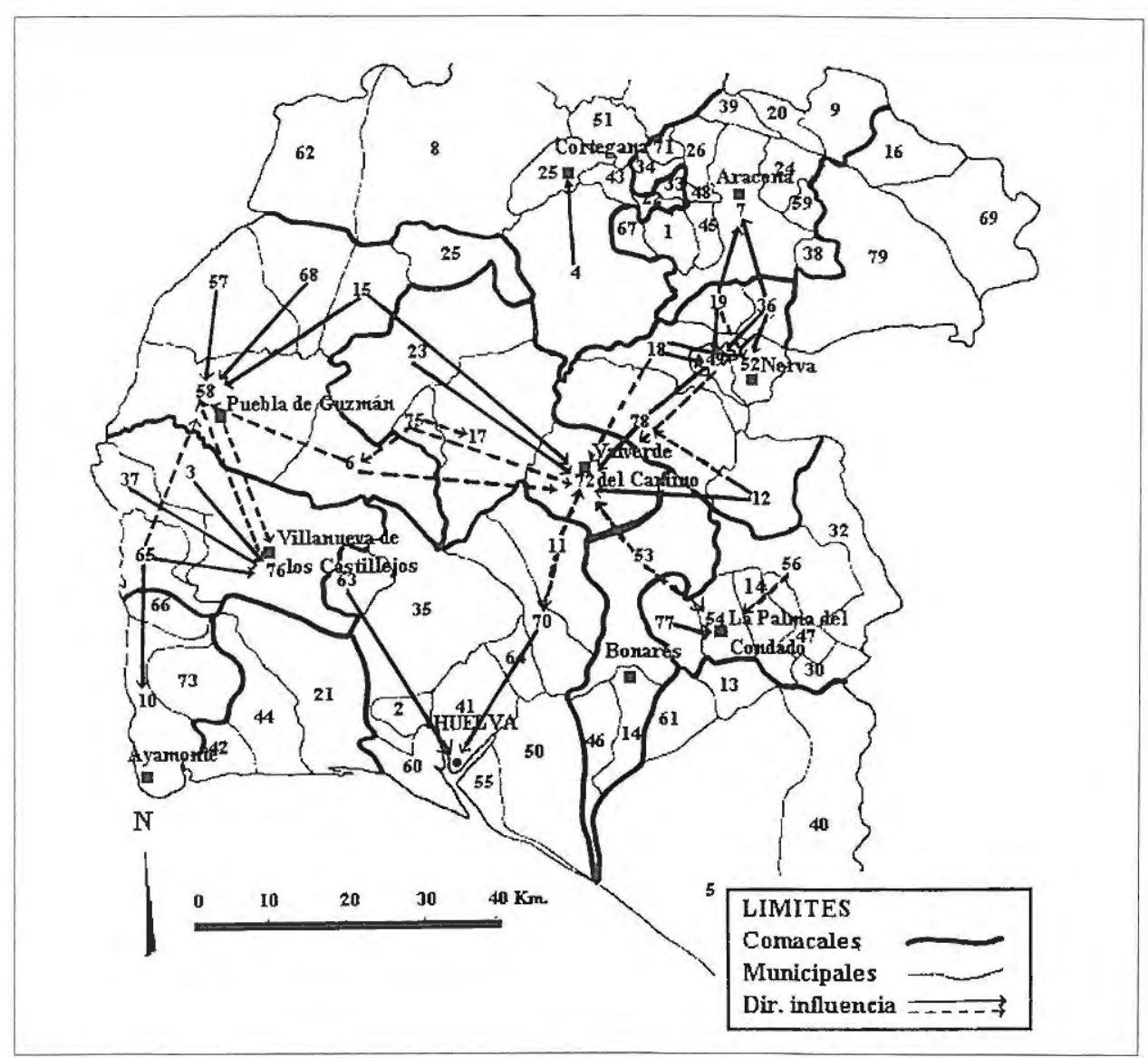

Límites y flujos en el Andévalo. Las comarcas se refieren a la propuesta de la Junta de Andalucía en 1983 y la equivalencia de números puede verse en el tomo octavo de la Geografía de Andalucía citada en el texto. 
Pueblo o ciudad donde se adquieren:

\section{ARTÍCULOS}

- Comestibles especializados

- Confección

- Zapatería

- Electrodomésticos

- Muebles

- Relojería, joyería

- Televisión, vídeos

- Droguería

- Ferretería

- Fotografía

- Deportes

- Material de construcción

- Ordenadores, informática

- Librería

- Loterías, quinielas, etc.

- Automóviles

- Bicicletas y motos

- Butano

- Moda y artesanía

- Optica

- Estanco

\section{GESTIONES}

- Administración autonómica

- Administración del Estado

- Bancos y Cajas de Ahorros

- Agencias de Seguros

- Correos

REPARACIONES Y SERVICIOS

- Autoescuelas

- Taxis
- Fontanería

- Carpintería

- Electricista

- Reparación coches

- Gasolinera

- Peluquería

- Tintorería

ADMINISTRACIÓN, ENSEÑANZA, ETC.

- Notarios

- Abogados

- Juzgados

- Guardia Civil

- INEM

- Extensión Agraria

- Universidad

- Centro BUP

- Centro FP

- Academias

- Colegios privados

- Ambulatorio

- Hospital

- Médico general

- Médico especialista

OTROS

- Discotecas

- Piscinas

- Restaurantes

- Prensa, revistas

¿A QUÉ COMARCA PERTENECE EL PUEBLO?

¿CUÁL ES LA CAPITAL DE ESA COMARCA?

Cartografiados los resultados del trabajo de campo realizado por los alumnos de Tercer Ciclo, resulta lo siguiente:

a) Los límites del Andévalo según los flujos quedan bastante nítidos: por el norte la carretera desde Paymogo al cruce con la de Huelva-Mérida enlaza una serie de 
pueblos y pedanías (Santa Bárbara, Cabezas Rubias, El Cerro, Valdelamusa, Cuevas de la Mora) que se orientan claramente hacia el sur. Almonaster se relaciona ya con Cortegana y, al este, Campofrío y La Granada se incluyen en el área de Riotinto-Nerva, pero también se desplazan a Aracena.

Al sur los límites con el Condado están definidos y las indagaciones en Paterna, Villalva y Villarrasa, próximas a La Palma, así lo confirman. También en Niebla, aunque existe alguna relación con Valverde; y Beas, en la carretera hacia ese centro industrial, marca la frontera, pues se consideran de la comarca del Condado, pero se relacionan también con Valverde. Hacia el oeste, los municipios de Alosno, El Almendro, Villanueva de los Castillejos y Sanlúcar se integran en el Andévalo, mientras San Bartolomé bascula claramente hacia la costa y significativamente se autoincluyen en una comarca denominada Andévalo-Costa.

b) La percepción de a qué comarca pertenece cada pueblo y cual es la capital arroja una mayoría de respuestas con denominación del Andévalo, incluso en pueblos de la Cuenca Minera, si bien se distingue entre la parte occidental y la oriental, sobre todo en los núcleos extremos, como Paymogo, por un lado, y Campillo, por otro. Y en el caso de Villanueva de las Cruces se apunta su carácter dudoso en cuanto a esa adscripción.

Si la percepción de el Andévalo como comarca es muy clara, no tanto su capitalidad; así, al este se suele señalar Valverde, incluso desde Riotinto, pero, a su vez, se indica como cabecera por otros pueblos, como Campillo. En el Andévalo occidental hay más confusión; los núcleos periféricos del norte (Paymogo, Cabezas Rubias...) asignan a Puebla de Guzmán y los del sur a Villanueva de los Castillejos, porque algunos entrevistados de estos dos centros sitúan la capital del Andévalo y/o de la parte occidental en la misma Huelva. Enmedio, además del comentado de El Almendro, Alosno, también en posición central, se inclina más por Valverde.

c) Lo anterior concuerda bastante con el mapa de enlaces. El que más tiene es Valverde con el que se relacionan de manera importante cinco núcleos (Berrocal, Zalamea, El Cerro del Andévalo, Cabezas Rubias y Calañas) y seis de forma más débil (Villanueva de las Cruces, Alosno, Campillo, Riotinto, Beas y Niebla). Se detectan desplazamientos desde casi todo el Andévalo por razones de la cabecera judicial, abogados, y para compra de muebles y calzado.

En la parte oriental destaca también Minas de Riotinto, cuya principal atracción radica en la existencia de hospital comarcal, centros de Enseñanza Media, Formación Profesional y poco más. Son La Granada, Campofrío, Campillo, Zalamea, Berrocal además de Nerva, más centro comercial, con la que comparte algunos enlaces.

En el occidente sobresalen dos pueblos, pequeños, pero es que se trata de una zona poco articulada y escasamente habitada. Puebla de Guzmán centra la parte norte con Cabezas Rubias (a caballo con Valverde), Santa Bárbara, Paymogo y, con 
relaciones más débiles, Alosno, El Almendro y Sanlúcar, que comparte con Villanueva de los Castillejos, en el sur. Después hay algún núcleo, como Calañas, Zalamea, Alosno... que mantiene un enlace con otro pueblo.

\subsection{Conclusiones}

El Andévalo es una penillanura basculada hacia el suroeste, de menguada fertilidad agrícola y abundante riqueza minera, esquilmada y en crisis actualmente, poco poblada, unos 60.000 habitantes, y núcleos en general pequeños (destacan Valverde con unos $12.000 \mathrm{~h}$. y Nerva en torno a 5.000), engarzados en carreteras comarcales de dirección transversal y una general norte-sur entre Huelva y Extremadura.

Valverde del Camino (cruce de vías y pueblo emprendedor con industria y artesanía moderna, y amplia oferta de bienes y servicios) debe ser potenciado para que centre realmente esta amplia zona. En la propuesta de la Junta de Andalucía de 1983 se considera capital de una comarca a la que se le une sólo Calañas y El Cerro del Andévalo. Sin embargo, hemos visto que Alosno, Villanueva de las Cruces y Cabezas Rubias enlazan con Valverde, pero también con la Puebla de Guzmán. Y, por el oriente, Вептоcal, un tanto aislado, casi está equidistante entre Valverde y Riotinto, mientras de éste quedan mucho más próximos El Campillo y Zalamea.

El desarrollo de Valverde como polo (que diversificaría su economía y reforzaría la conexión producción/servicios) no quita para que exista una comarca de la cuenca minera, actualmente a unos 20.000 h., donde, como hemos constatado, hay una polarización compartida entre Riotinto y Nerva, con algunos servicios también en Zalamea. Forma una Mancomunidad y tiene problemas comunes (crisis minera, deterioro ambiental y paisajístico, etc.) que aconsejan una cierta organización. Al oeste la desarticulación es mayor y las comunicaciones con Huelva son igual o mejor, según de qué pueblo se trate, que con Valverde. Así las relaciones con la capital provincial son fuertes y para adquisiciones menores hay, como vimos, dos polos, Puebla de Guzmán y Villanueva de los Castillejos, con área intermedia compartida. Ambos con poca población (tres y dos mil aproximadamente) y escasa oferta, pero cruces de caminos en un espacio desorganizado y de baja renta, cuya economía (desfavorecida por el Polo de Huelva y el olvido secular en una zona de frontera) es menester potenciar. La existencia de una Mancomunidad que agrupa toda esta parte del Andévalo puede significar un principio. 


\section{LA SIERRA SUR DE SEVILLA Y LA CONFLUENCIA PROVINCIAL ${ }^{4}$}

\subsection{Introducción}

Interesaba el análisis territorial de esta zona por varias razones. De un lado, contrastar las diferencias con la Sierra Norte sevillana, respecto a la cual, litología, altitud y, sobre todo topografía y suelos, permiten cultivos y, en consecuencia, han generado un poblamiento más denso. Y eso precisamente plantea de forma distinta la confluencia provincial Sevilla-Córdoba-Málaga, porque, en principio, puede suponerse que la Sierra Sur está centrada por Estepa, pero no muy lejos se encuentran Osuna, al oeste, y, además, relativamente próximas y bien comunicadas hay dos importantes polos en las otras provincias, Antequera y Puente Genil.

\subsection{Una Sierra suave y agraria}

Se trata de las estribaciones triásicas del Subbético andaluz formadas por margas, margo-calizas y areniscas, que (aunque existen algunos afloramientos salinos del Keuper y áreas endorreicas) producen en general unos suelos (regosoles y cambisoles cálcicos) aptos para el cultivo y presentan formas suaves de colinas (las altitudes mayores sobrepasan poco los 1.000 metros) y piedemontes; condiciones, pues, muy diferentes a la Sierra Norte.

El clima es más parecido al de Ia campiña sevillana, aunque con uno o dos grados menos de temperatura media anual, si bien el verano es similar, así como las precipitaciones. En suma, una zona tradicionalmente agraria, de secano, y una de las áreas clásicas de los movimientos jornaleros andaluces.

\subsection{Población y redes viarias}

Ha sido una comarca de fuerte emigración, aunque menos que la del Norte, con saldos negativos desde los años sesenta a finales de los setenta, cierta recuperación posterior y densidades superiores a Sierra Morena, como ocurre en el Subbético. La población de los diez municipios, que, según aparece en el gráfico 15 componen la "comarca" de Estepa, más los 12.000 de este núcleo suponen casi 50.000 habitantes, entre los dos y seis mil, salvo Lora que no alcanza los 800 .

Existe un eje fundamental que es la autovía 92, desde Osuna a Estepa y continuación hacia Antequera, en el que se insertan Aguadulce, Lora y La Roda de

4. Hicieron el trabajo de campo: V. CABALLERO, A. CHICA y C. JANEIRO. Curso 1994-95. 


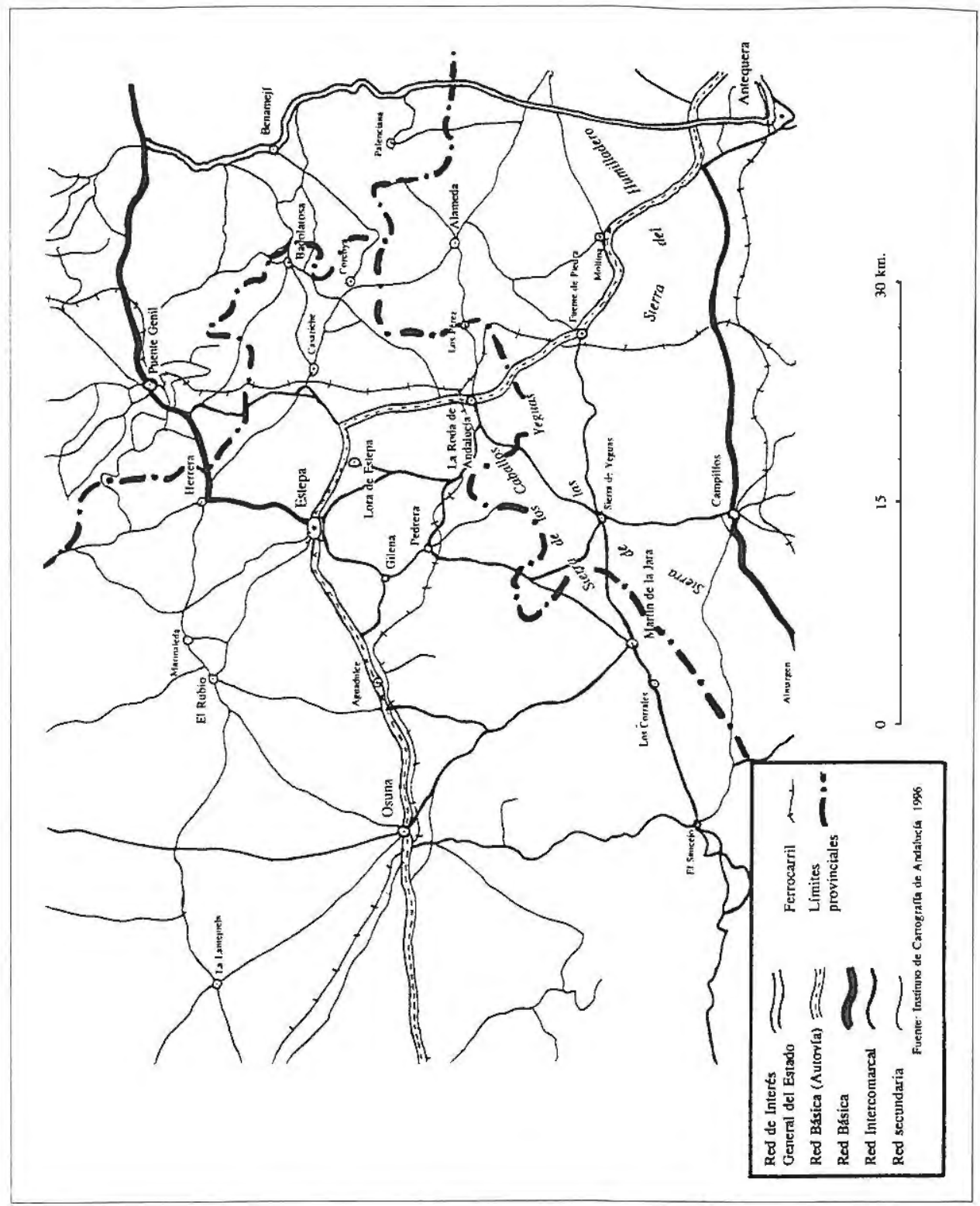

Andalucía, quedando próximos Herrera, Casariche, Gilena y Pedrera. Por su parte, Martín de la Jara, Los Corrales y El Saucejo enlazan con Estepa por carretera comarcal, al igual que Marinaleda y El Rubio. Badolatosa, en los límites con Córdoba, queda más alejada. 


\subsection{Divisiones provinciales y municipales}

La alineación sierra de los Caballos-El Tablón viene a marcar aproximadamente la separación Sevilla-Málaga con dos especie de "intromisiones" hacia el norte por Sierra de Yeguas y Alameda, que abarcan una parte montañosa, pero los núcleos se sitúan al sur. A los lados de la línea quedan sendos ejes (Morón-SaucejoLa Roda y Olvera-Campillos-Antequera) conectados a través de un relieve tenue, que posibilita las relaciones comarcales interprovinciales.

Entre Sevilla y Córdoba actúa de divisoria el Genil, salvo en el municipio de Puente Genil que, significativamente, avanza hacia el oeste para dejar al río como

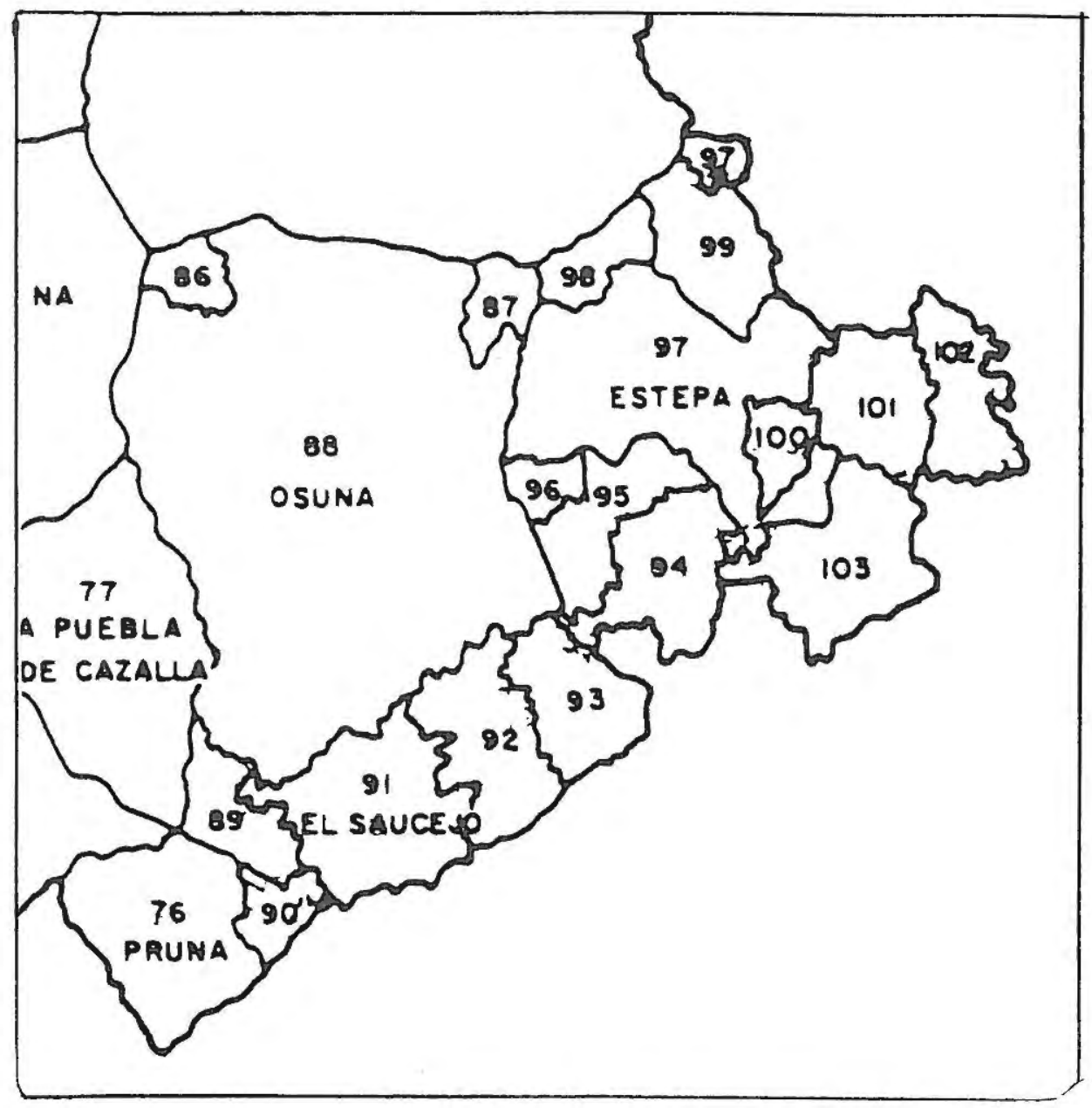

Divisiones municipales al sur de la provincia de Sevilla. Véase Tomo VIII de la Geografía de Andalucía. 
eje del término, igual que ocurre más al norte con Ecija. Tampoco aquí hay obstáculos naturales que impidan la relación entre las dos demarcaciones de 1833.

La división municipal es importante en una zona agraria, porque la extensión de los términos posibilita en principio un mayor o menor crecimiento de los núcleos. Hay, sobre todo en la parte sevillana, unas claras circunscripciones originarias de las que han ido surgiendo otras y, en general, se nota coincidencias entre la división municipal y las áreas de influencia. Así el término de Osuna sigue siendo uno de los mayores y en su extremo norte se segregaron La Lantejuela y El Rubio. Todavía Estepa conserva bastante extensión, a pesar de la orla de Marinaleda, Неrrera, Lora, Aguadulce... Así mismo el extenso término de Antequera queda disminuido por Mollina, Humilladero, Fuente de Piedra... y en Córdoba Lucena está limitada por Palenciana, Benamejí, Encinas Reales...

\subsection{Homogeneidad e historicidad}

El criterio de homogeneidad une en alguna variable las comarcas de Estepa y Osuna, pero en más casos aparecen separadas, aunque no siempre con los municipios propuestos por la Junta de Andalucía en 1983. Según algunos parámetros, Estepa coincide más con la parte SW de Córdoba, si bien ésta suele ostentar mayor heterogeneidad en general, y las diferencias con Antequera son más que las semejanzas. Los límites históricos (op. cit.) remarcan las dos comarcas sevillanas, en la que Osuna (alejada de los grandes núcleos (Sevilla, Córdoba, Málaga) cuenta con una larga tradición urbana.

\subsection{Polarización y áreas de influencia}

Hemos cartografiado esquemáticamente los resultados del trabajo de campo realizado, separando por bloques de bienes y servicios, en croquis con los cuatro centros importantes de la zona (Osuna, Estepa, Puente Genil y Antequera) y todos los núcleos sevillanos de esta Sierra Sur. Carecemos de información homologable al resto sobre El Rubio, si bien sabemos que su comportamiento en el aspecto que tratamos es similar al de Marinaleda.

Para empezar, y a efectos metodológicos, indicar que suprimimos algunos mapas: el relativo a fontanería, carpintería, talleres de electricidad, etc. porque no generaban áreas de influencia; apenas existen desplazamientos por razones de ocio (discotecas, restaurantes, piscinas...) y, menos, en relación a entidades financieras y seguros.

En los demás hay una notable diferencia entre las conexiones administrativas y de servicios públicos, donde se imponen los límites provinciales, y las de adquisi- 


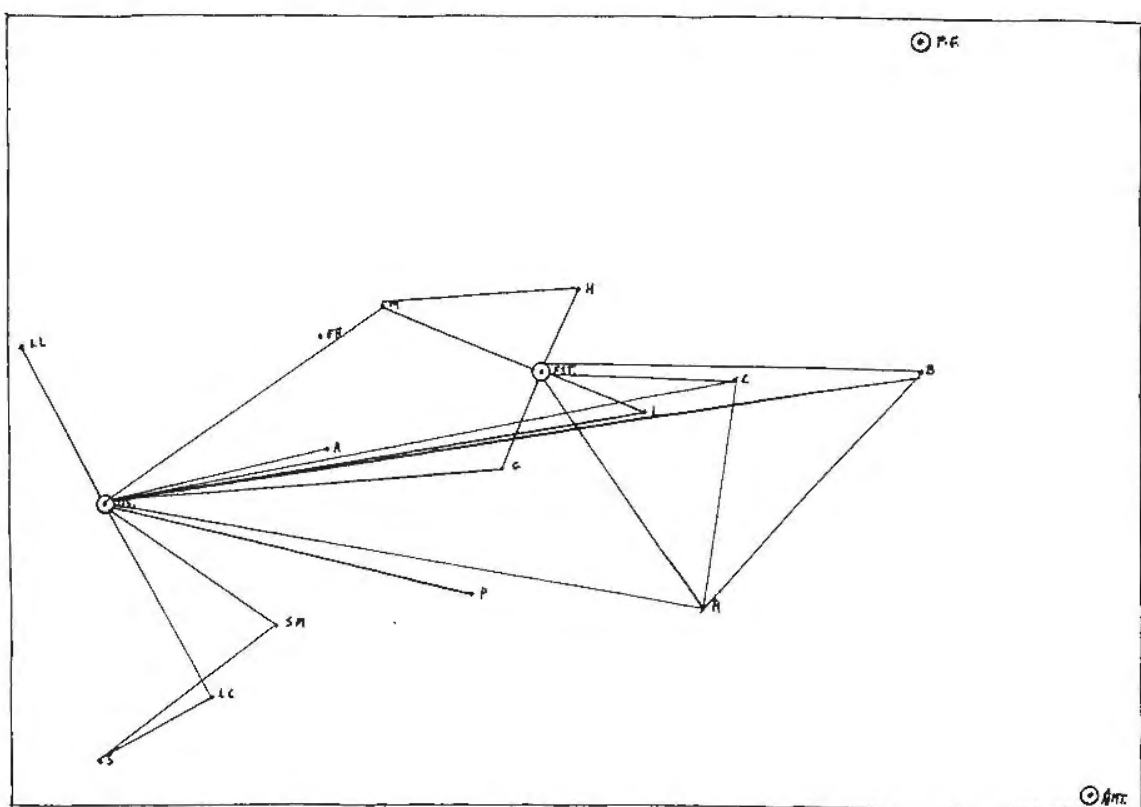

Desplazamientos desde pueblos los de la Sierra Sur a Estepa, Osuna, Puente Genil y Antequera para gestiones de administración autonómica y estatal, INEM y Extensión Agraria.

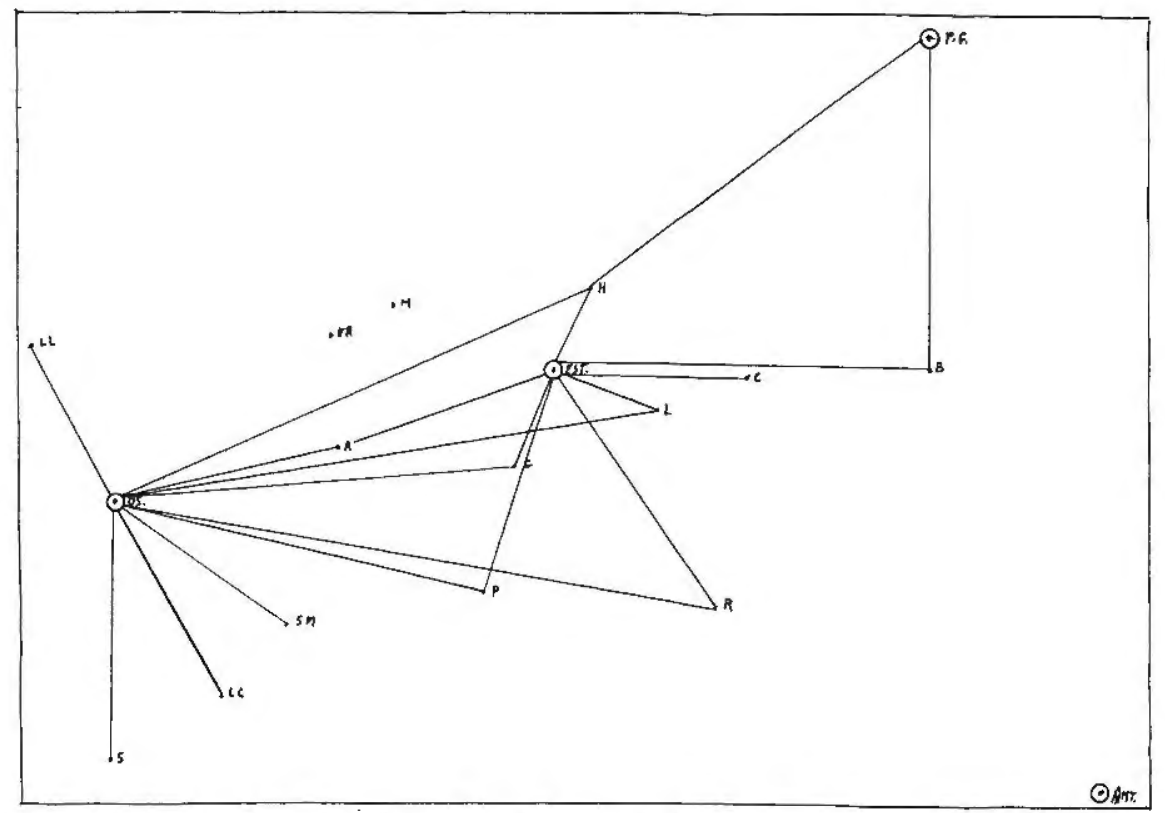

Idem para Juzgados, Notarios, Abogados y Guardia Civil. 


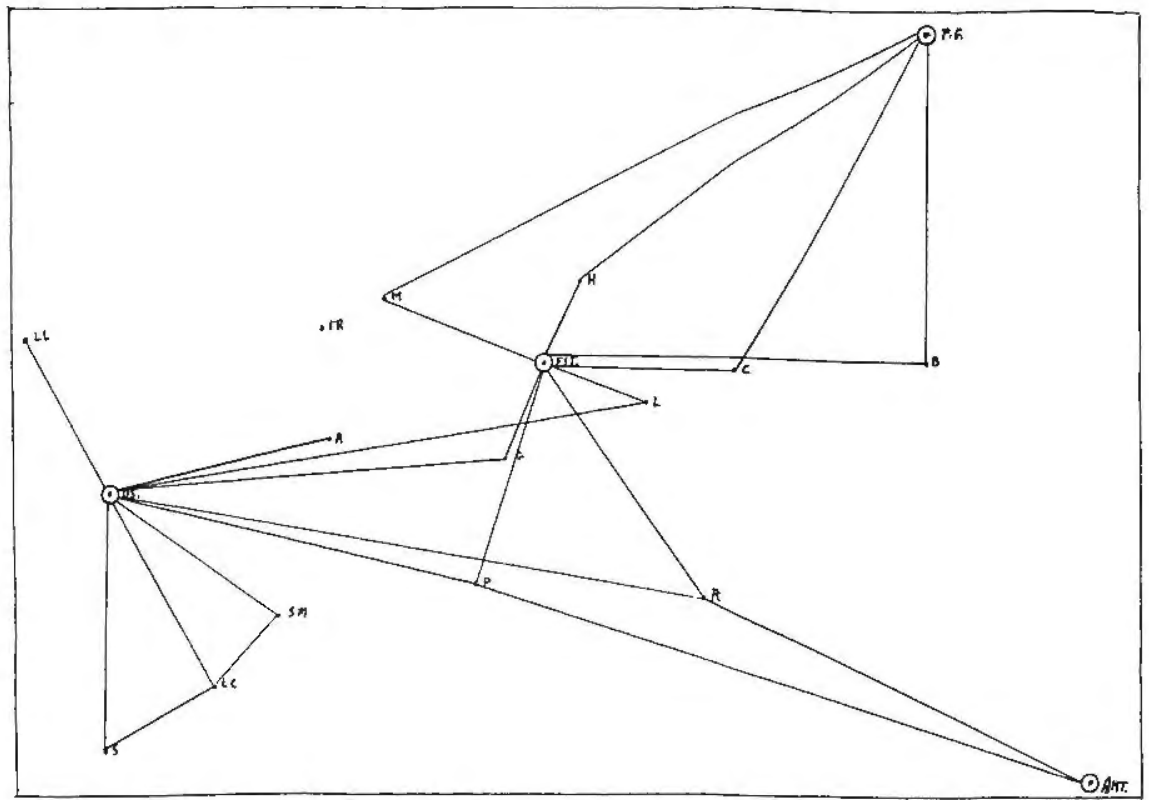

Relaciones de la Sierra Sur con los cuatro centros indicados para enseñanza universitaria, BUP, FP, Academias y Colegios privados.

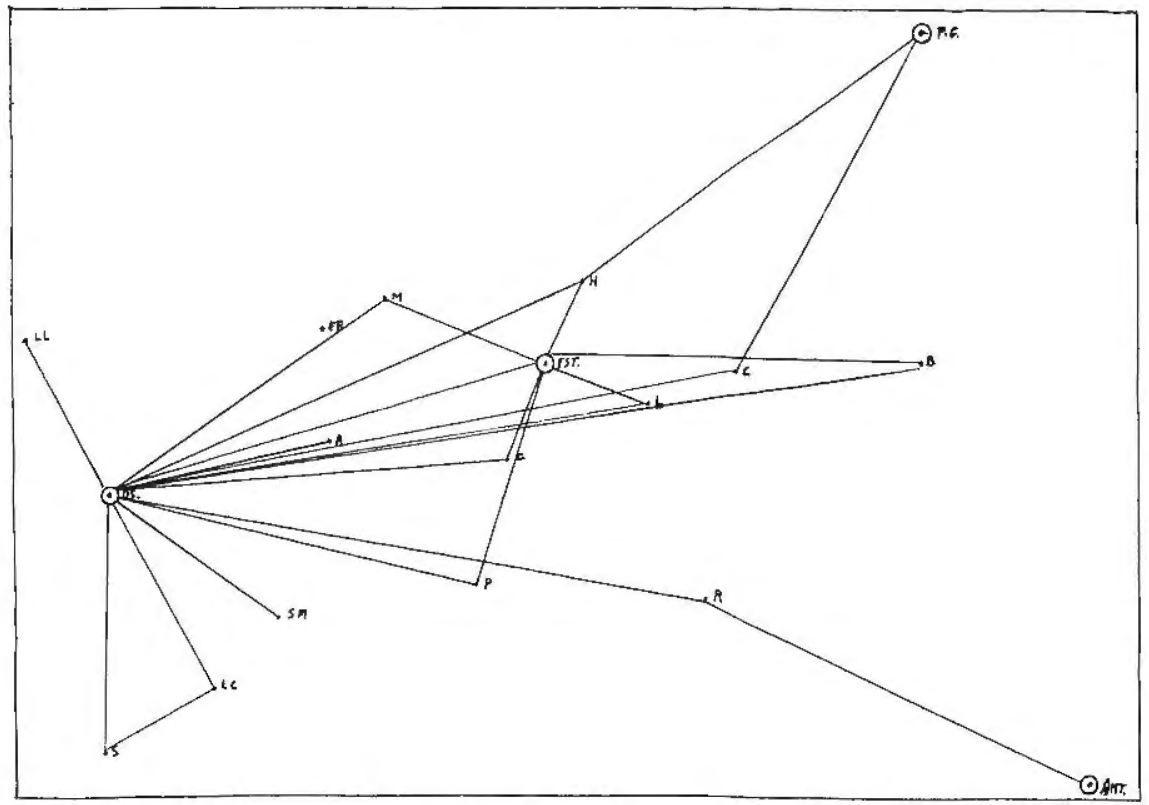

Idem para ambulatorios, Hospital, Médicos y opticas. 
ción de bienes y servicios de empresas privadas. El ejemplo más claro de lo primero es el mapa de desplazamientos para gestiones administrativas, INEM, Extensión Agraria..., pero también el de Jnzgados, Guardia Civil, notarios y abogados, siendo las consultas a estos últimos los que explican algunos viajes a Puente Genil. Así mismo, en el caso de Colegios privados, para los que se acude también a Antequera desde los pueblos más próximos (mapa centros de BUP, F.P., academias...) o para consultas a médicos, mientras que el hospital comarcal de Osuna justifica las líneas con prácticamente todos estos pueblos. Porque, en general, y como es lógico, muchos de los enlaces se explican por las distancias en tiempo. Es significativo también las semejanzas de conexiones en los mapas comerciales, aunque no en tv, vídeo... automóviles, donde Antequera recibe menos clientes de esta zona.

En cambio los pueblos cordobeses y malagueños próximos no tienen relación con los polos sevillanos; tan sólo en los limítrofes de Almargen, Teba y Fuente Piedra se detecta alguna conexión con Los Corrales, La Roda y otros.

Aunque los cuatro centros se marcan en los diferentes croquis, los resultados finales difieren, pues el número de enlaces que tiene Osuna (73) está alejado de Antequera (14), a la vez que Estepa (64) duplica a Puente Genil. Es decir, que, a pesar de todo, los límites provinciales influyen, además de las distancias. A su vez, son autosuficientes, salvo en las dependencias respecto a las capitales provinciales; incluso Puente Genil, más o menos equidistante, envía universitarios a Córdoba, Sevilla y Málaga. Estepa además utiliza el Hospital comarcal de Osuna.

Antequera es una ciudad con más de 30.000 habitantes, centro geográfico de Andalucía, cruce viario (enlaza el Valle del Guadalquivir, la Depresión intrabética y la costa), urbe agraria, comercial y de servicios. Parece que polariza más de lo que la propuesta comarcal de la Junta de Andalucía le otorgaba en 1983; al menos el área de Campillos y, por ceñirnos a la Sierra sur sevillana, una parte se relaciona con el núcleo malagueño, de mayor oferta que Estepa. Así La Roda, Pedrera, San Martín, Los Corrales y El Saucejo conectan con Antequera, sobre todo en la compra de artículos de cierta especialización y, menos, en colegios privados y médicos.

De otro lado, los resultados de las encuestas indican que Estepa (con la mayoría de bienes y servicios del cuestionario, una famosa industria de dulces y más de 10.000 habitantes) organiza el área propuesta por la Junta en 1983. Pero, además de lo indicado para el sur con Antequera, la parte norte del área estepeña se relaciona bastante con Puente Genil y el Oeste, Aguadulce sobre todo, lo comparte con Osuna (unos $20.000 \mathrm{~h}$. y mayor oferta que Estepa), que centra claramente a la parte occidental de la Sierra.

Por su parte Puente Genil atrae a Herrera, Casariche, Badolatosa y otros más alejados, sobre todo por la oferta de muebles, con lo que la distribución comarcal de la Junta en el suroeste cordobés es bastante discutible. Pero en el caso de la 


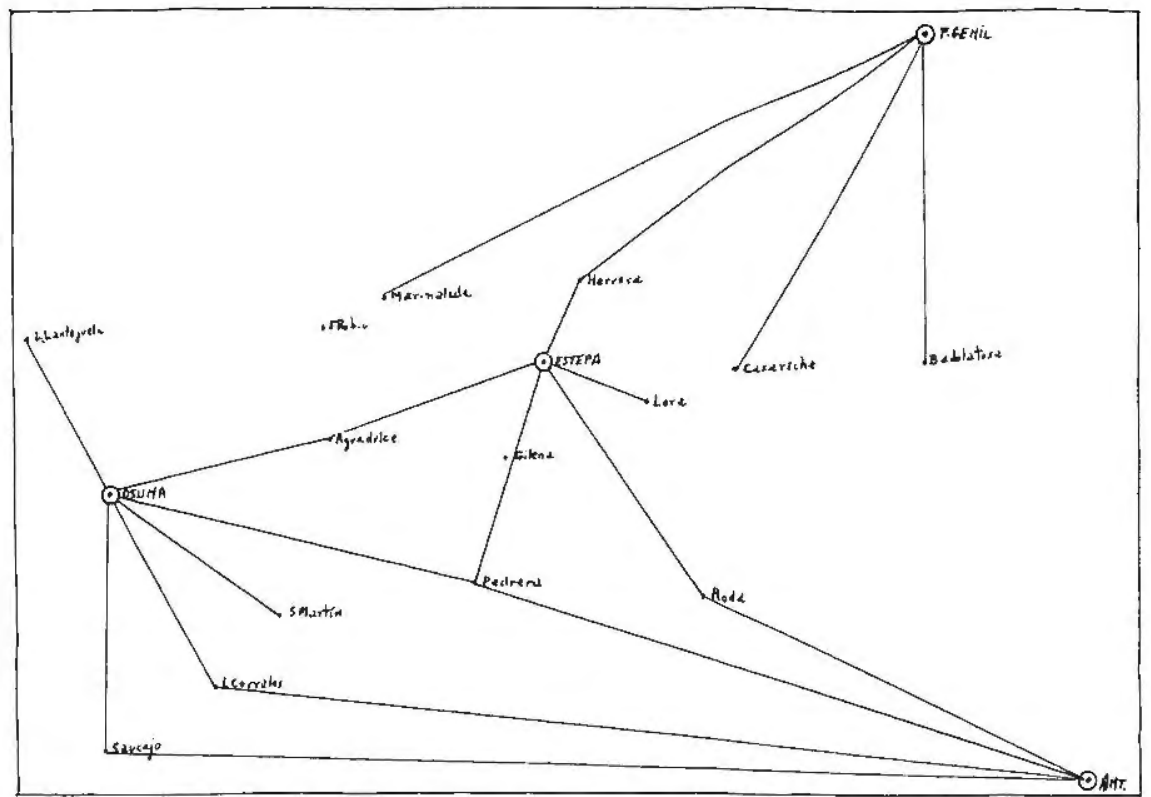

Desplazamientos a Estepa, Osuna, Puente Genil y Antequera para adquisición de comestibles especializados, confección y zapatería.

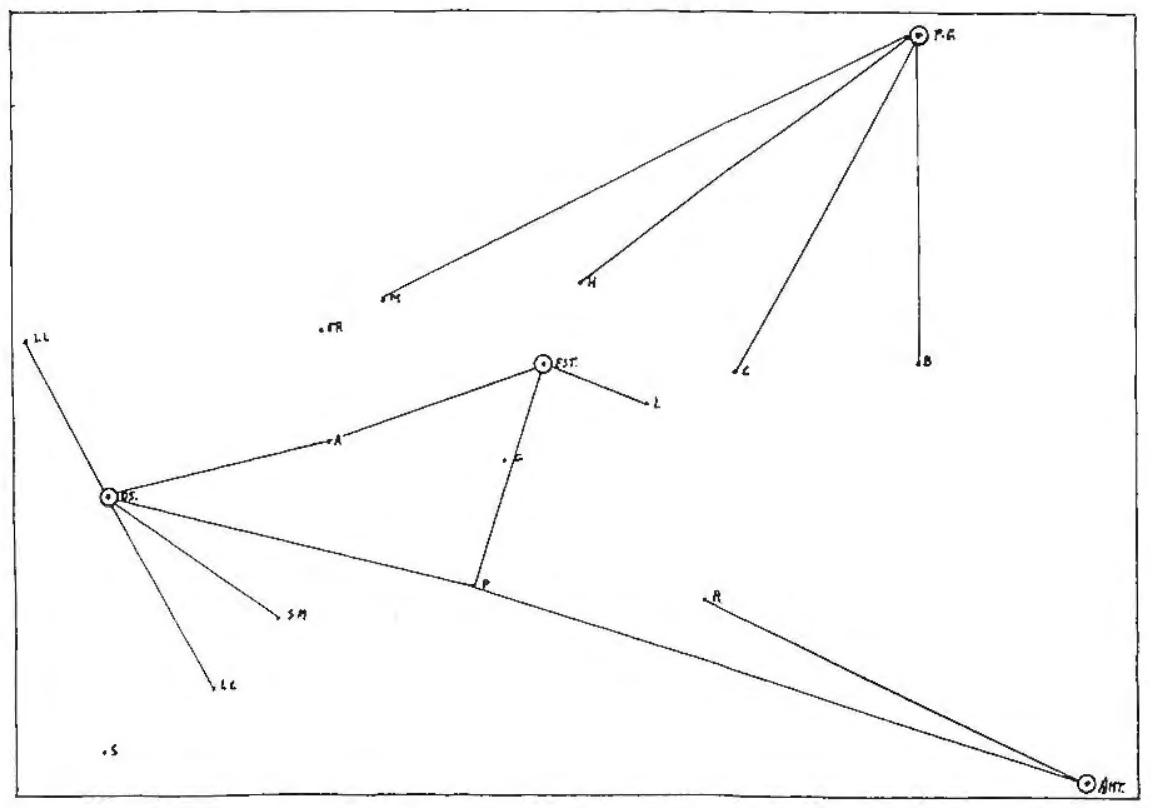

Idem para compras en la relojería, joyería, modas y artesanía. 


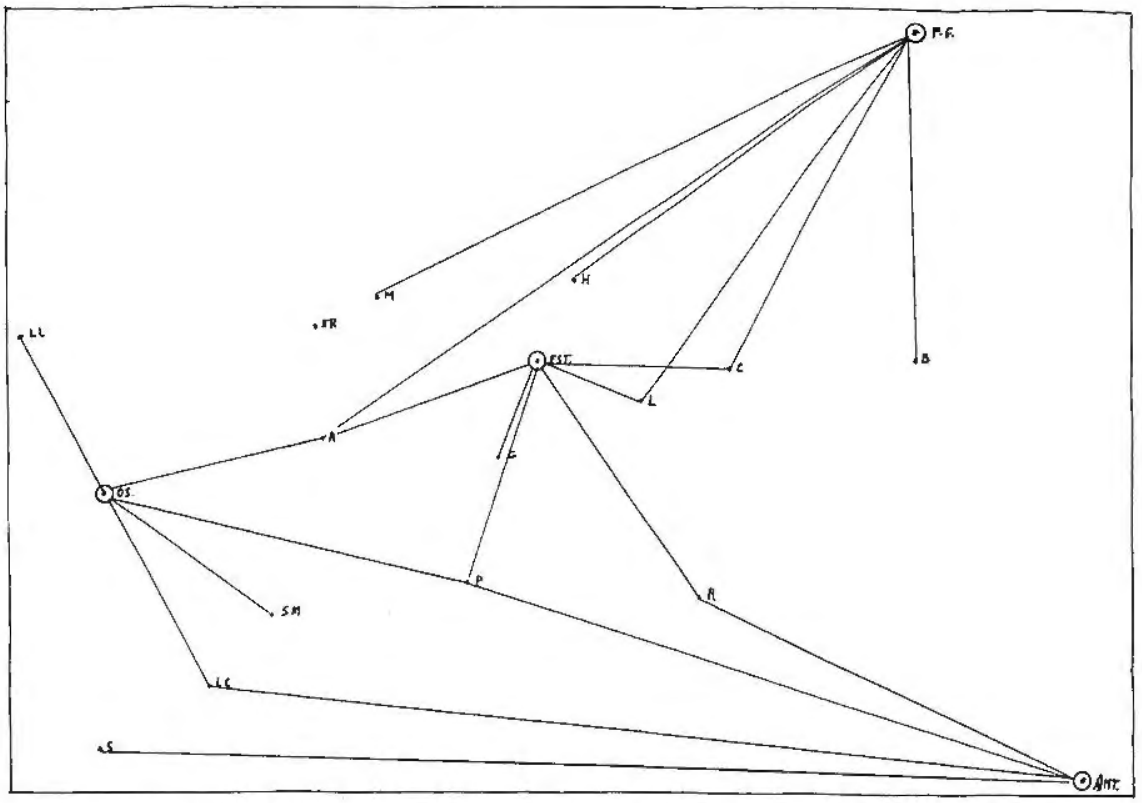

Relaciones de la Sierra Sur con los cuatro centros indicados para adquisición de artículos de fotografía, deportes, informática y librería.

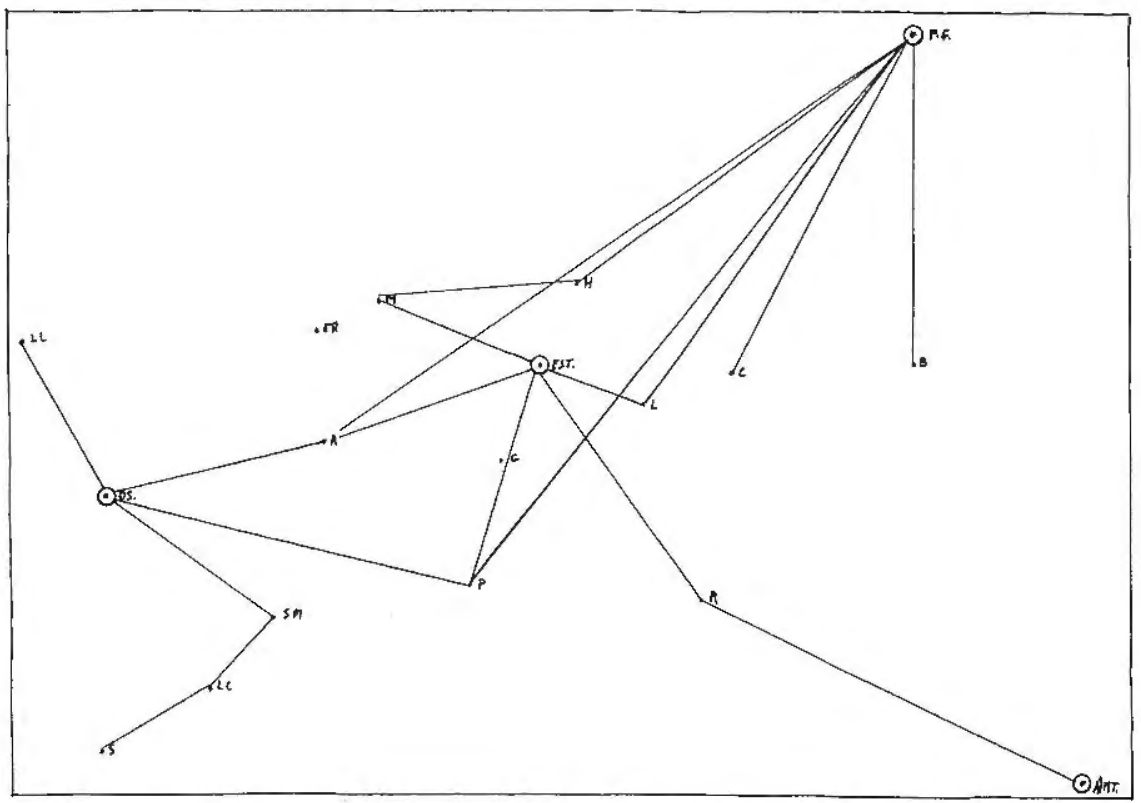

Idem para electrodomésticos, TV, vídeo, muebles y butano. 


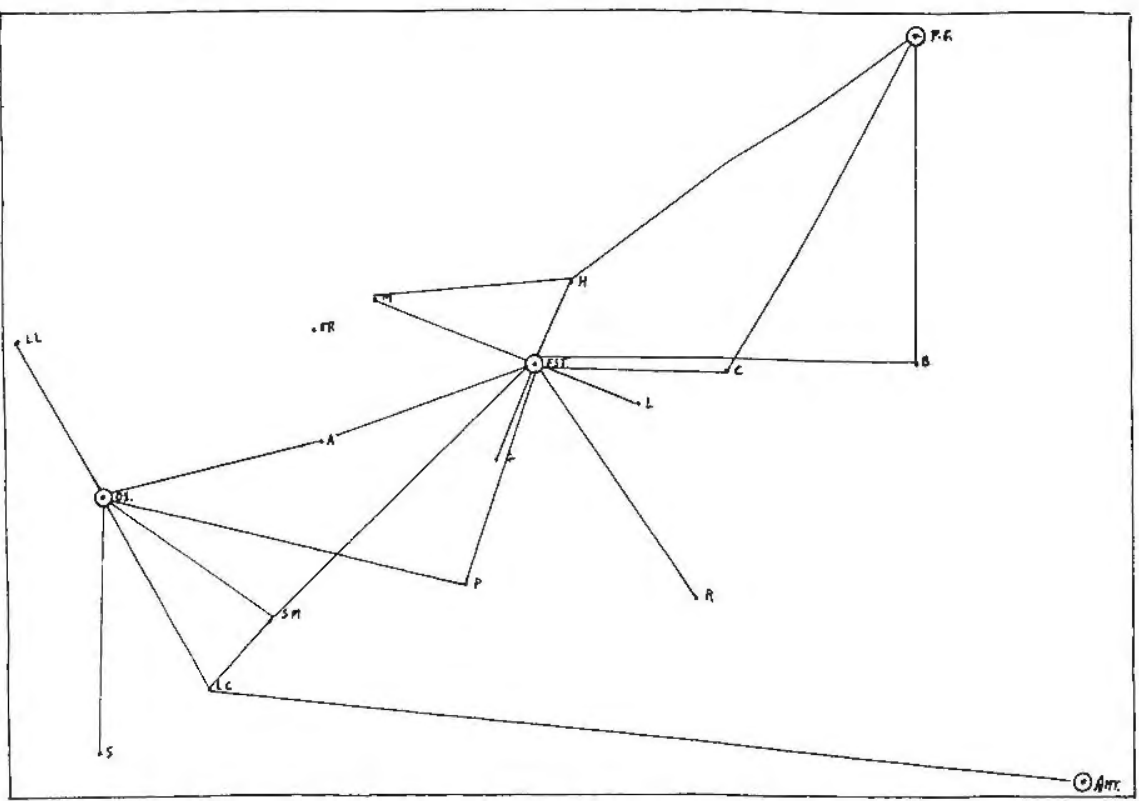

Desplazamientos desde pueblos de la Sierra Sur a Estepa, Osuna, Puente Genil y Antequera para la compra de coches, motos y bicicletas.

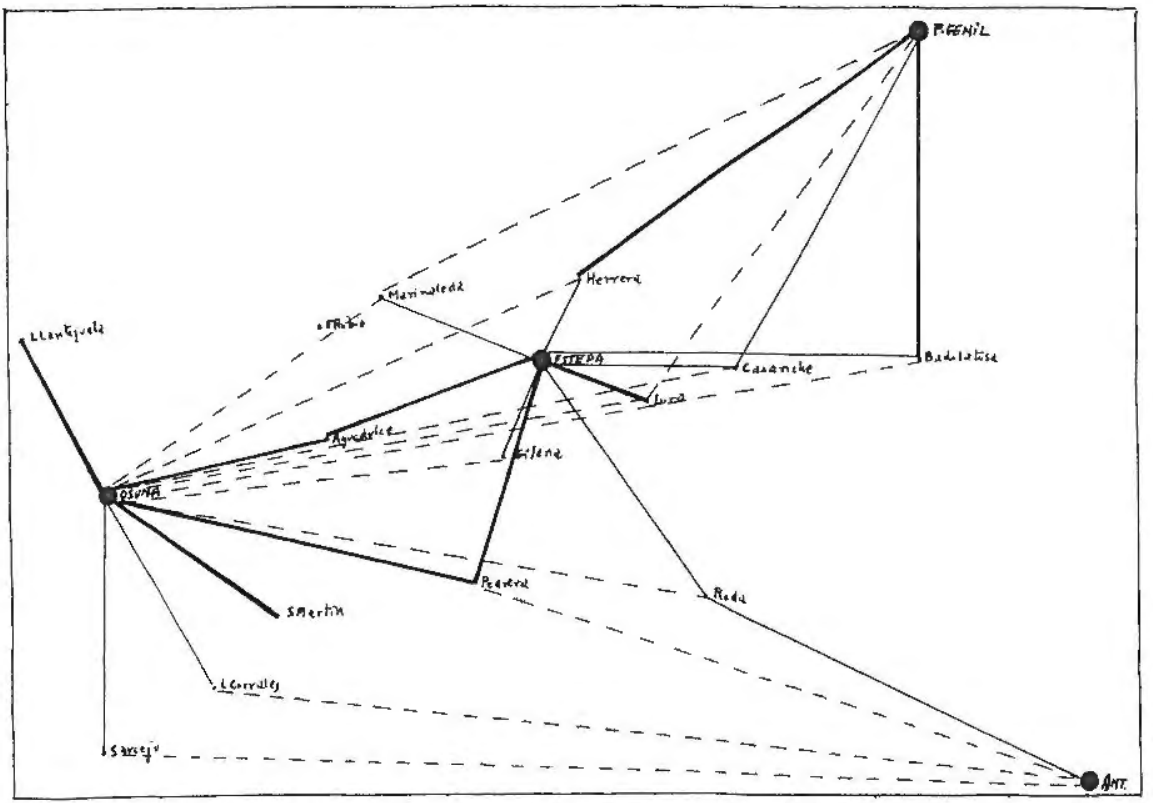

Intensidad de relaciones por todos Ios conceptos desde los pueblos de la Sierra Sur a Estepa, Osuna, Puente Genil y Antequera. Línea discontínua hasta cuatro enlaces; raya contínua de 5 a 8 ; y trazo grueso de 9 a 14 conexiones. 
Sierra sur de Sevilla hay un claro centro que es Estepa, si bien la periferia se relaciona con Osuna, Antequera y Puente Genil, por lo que la división provincial no es muy rígida en esta confluencia carente de grandes divisorias naturales.

\section{CONCLUSIONES}

Tras el estudio de cuatro modelos territoriales andaluces podemos extraer algunas consecuencias. En primer lugar, las Sierras Norte y Sur de Sevilla tienen comportamientos distintos, derivados en gran parte del relieve, pues en la primera la constitución litológica y topográfica no ha generado una agricultura que pueble la zona, como en el Sur, a pesar de abundar el secano, y la pretérita explotación minera no ha sido suficiente.

Sierra Morena constituye a lo largo del tiempo una frontera natural y la ciudad de Sevilla está más próxima, mientras que Osuna, Estepa, Antequera y Puente Genil, a mayor distancia de los grandes centros y en pleno corazón de Andalucía, cuentan con amplias trayectorias históricas y organizan unos espacios de forma muy diferente a Cazalla y Constantina. Por si fuera poco, los obstáculos naturales en la zona meridional no son comparables con los escarpes de Sierra Morena y la incisión fluvial, que entorpece los enlaces transversales. Así, aunque no existiesen los límites provinciales la influencia de los centros septentrionales alcanzan poco, al revés de lo que ocurre al sur, donde las demarcaciones administrativas de 1833 pesan precisamente en servicios determinados y apenas en comercio y otros bienes.

La Sierra Norte, no obstante, puede obtener hoy ventajas de la cercanía metropolitana, «vendiendo» recursos hídricos y Parque Natural, además de la potenciación de industrias cámicas, por ejemplo. La existencia de una Mancomunidad, o embrión de "comarca", servirá sin duda para una organización conjunta que desarrolle y conserve la zona. En cambio la Sierra Sur continuará su propia articulación territorial centrada por Estepa y Osuna, si bien, a la hora de una comarcalización debe tenerse muy presente la influencia de Antequera y Puente Genil.

La atracción de Sevilla y Jerez, por otra parte, dejan pocas posibilidades a la parte media del eje, limitado por la marisma al oeste, aunque cuenta con un importante núcleo, cuya "comarca" parece depender del iniciado protagonismo de Lebrija como polo de industrias y servicios agrarios, más el encabezamiento de iniciativas institucionales.

El Andévalo es un área periférica por su situación y características. De un lado, se localiza en el extremo andaluz con la frontera del Algarve al oeste, separado de la Sierra al norte, el área de influencia de Sevilla al este y Huelva y la costa al sur; es decir, con escasos márgenes de articulación propia. De otro, no es un terreno muy apto para la agricultura y, por ende, tradicionalmente poco poblado, salvo los 
centros mineros, que no han vertebrado el espacio (en general la minería no suele ser "territorializadora"), y la excepción de Valverde del Camino núcleo industrial. Parece clara la necesidad de potenciar este centro desde la administración pública y mejorar la accesibilidad de la zona, mientras que el extremo occidental, de pequeños pueblos, tendrá que encontrar otras vías, precisamente aprovechando su carácter fronterizo en la política económica europea...

\section{BIBLIOGRAFÍA CITADA}

ÁVILA: Campofrío. Una forma de vida entre la sierra y la mina, Huelva, Instituto de Estudios Onubenses, 1981, $105 \mathrm{pp}$.

CANO GARCÍA (Director): Geografía de Andalucía, Sevilla, Ed. Tartessos, 1987-90, ocho tomos.

CANO GARCÍA: "La provincia de Huelva. Un proceso de territorialización", Huelva en su historia, $\mathrm{n}^{2}$ 4, 1992, pp. 17-34.

DÍAZ DEL OLMO: "El Andévalo", Huelva y su provincia, Ed. Tartessos, 1986, 325 pp.

ESTUDIOS GEOGRÁFICOS ANDALUCES (Director G. CANO): "Areas gravitacionales andaluzas", Revista de Estudios Andaluces, 1994, pp. 214-224.

GIL VARON: Mineria y migraciones. Riotinto, 1873-1993. Córdoba Tip. Católica, 1984, 241 pp.

JORDA, R.: "El indicador dinámico de la población", Geografía de Andalucía, Op. Cit., Tomo VIII.

JUNTA DE ANDALUCÍA, Sistema de ciudades, Sevilla, 1986, 2 vol.

JURADO y MIRANDA: "Evolución de los centros históricos andaluces", Geografía de Andalucía, Op. Cit., Tomo VIII.

LÓPEZ LARA: "Zonificación de los accesos", Op. Cit.

LÓPEZ PÉREZ: "Areas según estructura de la propiedad", Op. Cit.

MARCHENA GÓMEZ: "Usos del suelo y densidad agraria", Geografía de Andalucia, Op. Cit.

MÁRQUEZ FERNÁNDEZ: La geoeconomía forestal de Huelva y el dilema de sus eucaliptales, Sevilla, I.D.R., 1977.

MÁRQUEZ DOMÍNGUEZ: "Ofertas comerciales", Op. Cit. tomo VIII.

MARTÍN RUIZ, P.: Comentarios sobre la comarca "Sierra Norte" de Sevilla y su plan de mejora, Madrid, Ministerio de Agricultura, 1975?, 94 pp.

NAVARRO LUNA: "Distribución de la Administración", Geografía..., Op. Cit.

OJEDA RIVERA: "Configuración provincial", Huelva y su provincia, op. cit.

POSADAS y GARCÍA GÓMEZ: "Límites más frecuentes en Andalucía a lo largo del tiempo", Geografía de Andalucía, Op. Cit., Tomo VIII.

REQUENA SÁNCHEZ, D.: Permanencia y cambio en la Sierra Norte de Sevilla, 1981-92, Sevilla, Grupo de Investigación "Estudios Integrados en Geografía", 1993, 82 pp.

VENTURA FERNÁNDEZ: "Ambitos educativos", Geografía de Andalucía, Op. Cit. 